\title{
SHEA Guideline for Management of Healthcare Workers Who Are Infected with Hepatitis B Virus, Hepatitis C Virus, and/or Human Immunodeficiency Virus
}

\author{
David K. Henderson, MD; Louise Dembry, MD, MS, MBA; Neil O. Fishman, MD; Christine Grady, RN, PhD; \\ Tammy Lundstrom, MD, JD; Tara N. Palmore, MD; Kent A. Sepkowitz, MD; David J. Weber, MD, MPH; \\ for the Society for Healthcare Epidemiology of America
}

\section{EXECUTIVE SUMMARY}

This guideline provides the updated recommendations of the Society for Healthcare Epidemiology of America (SHEA) regarding the management of healthcare providers who are infected with hepatitis $\mathrm{B}$ virus (HBV), hepatitis $\mathrm{C}$ virus (HCV), and/or the human immunodeficiency virus (HIV). For the reasons cited in the guideline, SHEA continues to recommend that, although some aspects of the approach to and administrative management of each of these infectious syndromes in healthcare providers are similar, separate management strategies for healthcare workers who are infected with these unrelated viruses remain appropriate. As we did in both prior iterations of this document, SHEA emphasizes the use of appropriate infection control procedures to minimize exposure of patients or providers to blood, emphasizes that transfers of blood from patients to providers and from providers to patients should be avoided, and recommends that infected healthcare providers should not be totally prohibited from participating in patient-care activities solely on the basis of a bloodborne pathogen infection. The types of procedures assessed by the panel as associated with an increased risk for provider-to-patient transmission of these pathogens are discussed in detail. For each pathogen, recommendations are graduated according to the relative viral load level of the infected provider (Tables 1 and 2). However, SHEA emphasizes that, because of the complexity of these cases, each such case will be slightly different from the next, and each should be independently considered in context.

\section{HBV}

SHEA recommends that $\mathrm{HBV}$-infected healthcare providers who test either positive for HBV "e" antigen ( $\mathrm{HBeAg}$ ) or negative for HBeAg but who have circulating HBV burdens of greater than or equal to $10^{4}$ genome equivalents (GE) per milliliter of blood routinely use double-gloving for all invasive procedures, for all contact with mucous membranes or nonintact skin, and for all instances in patient care for which gloving is recommended, and that they not perform those Category III activities identified as associated with a risk for provider-to-patient HBV transmission despite the use of appropriate infection control procedures (details of the procedures identified as associated with increased risk for transmission are given in Table 2).

SHEA recommends that a healthcare provider who has a circulating HBV burden of less than $10^{4} \mathrm{GE} / \mathrm{mL}$ be allowed to perform those Category III activities identified as associated with a risk for provider-to-patient transmission of bloodborne pathogens, so long as the infected provider (1) is not detected as having transmitted infection to patients; (2) obtains advice from an Expert Review Panel (the function of the Expert Review Panel is discussed in more detail in Recommendation 8, below) about continued practice; (3) undergoes follow-up routinely by Occupational Medicine staff (or an appropriate public health official), who test the provider twice per year to demonstrate the maintenance of a viral burden of less than $10^{4} \mathrm{GE} / \mathrm{mL}$; (4) also receives followup by a personal physician who has expertise in the management of HBV infection and who is allowed by the provider to communicate with the Expert Review Panel about the provider's clinical status; (5) consults with an expert about optimal infection control procedures (and strictly adheres to the recommended procedures, including the routine use of double gloving for Category II and Category III procedures and frequent glove changes during procedures, particularly

From the National Institutes of Health Clinical Center, Bethesda, Maryland (D.H.), the Department of Quality Improvement Support Services, Yale-New Haven Hospital, New Haven, Connecticut (L.D.), the Division of Infectious Diseases, University of Pennsylvania School of Medicine, Philadelphia, Pennsylvania (N.F.), the Department of Bioethics, National Institutes of Health Clinical Center, Bethesda, Maryland (C.G.), the Section of Infectious Diseases, Providence Hospital and Medical Center, Southfield, Detroit, Michigan (T.L.), the Infectious Disease Fellowship Training Program, National Institutes of Health Clinical Center, Bethesda, Maryland (T.P.), Infectious Diseases Service, Memorial Sloan-Kettering Cancer Center, New York, New York (K.S.), and the Division of Infectious Diseases, University of North Carolina, Chapel Hill, North Carolina (D.W.). Note: A statement about authorship appears at the end of the text.

Received November 10, 2009; accepted November 23, 2009; electronically published January 20, 2010.

(C) 2010 by The Society for Healthcare Epidemiology of America. All rights reserved. 0899-823X/2010/3103-0001\$15.00. DOI: 10.1086/650298 
TABLE 1. Summary Recommendations for Managing Healthcare Providers Infected with Hepatitis B Virus (HBV), Hepatitis C Virus (HCV), and/or Human Immunodeficiency Virus (HIV)

\begin{tabular}{|c|c|c|c|}
\hline $\begin{array}{l}\text { Virus, } \\
\text { circulating viral burden }\end{array}$ & Categories of clinical activities ${ }^{\mathrm{a}}$ & Recommendation & Testing \\
\hline \multicolumn{4}{|l|}{ HBV } \\
\hline$<10^{4} \mathrm{GE} / \mathrm{mL}$ & Categories I, II, and III & No restrictions ${ }^{\mathrm{b}}$ & Twice per year \\
\hline$\geqslant 10^{4} \mathrm{GE} / \mathrm{mL}$ & Categories I and II & No restrictions $\mathrm{s}^{\mathrm{b}}$ & NA \\
\hline$\geqslant 10^{4} \mathrm{GE} / \mathrm{mL}$ & II & tricted $^{c}$ & NA \\
\hline \multicolumn{4}{|l|}{$\mathrm{HCV}$} \\
\hline$<10^{4} \mathrm{GE} / \mathrm{mL}$ & Categories I, II, and III & No restrictions ${ }^{\mathrm{b}}$ & Twice per year \\
\hline$\geqslant 10^{4} \mathrm{GE} / \mathrm{mL}$ & Categories I and II & No restrictions ${ }^{\mathrm{b}}$ & NA \\
\hline$\geqslant 10^{4} \mathrm{GE} / \mathrm{mL}$ & & & NA \\
\hline \multicolumn{4}{|l|}{ IIV } \\
\hline$<5 \times 10^{2} \mathrm{GE} / \mathrm{mL}$ & ies I, II, and III & No restrictions ${ }^{\mathrm{b}}$ & Twice per year \\
\hline$\geqslant 5 \times 10^{2} \mathrm{GE} / \mathrm{mL}$ & d II & No restrictions ${ }^{\mathrm{b}}$ & NA \\
\hline$\geqslant 5 \times 10^{2} \mathrm{GE} / \mathrm{mL}$ & Category III & Restricted $^{\mathrm{d}}$ & \\
\hline \multicolumn{4}{|c|}{$\begin{array}{l}\text { NOTE. These recommendations provide a framework within which to consider such cases; however, each } \\
\text { such case is sufficiently complex that each should be independently considered in context by the expert review } \\
\text { panel (see text). GE, genome equivalents; NA, not applicable. } \\
\text { a See Table } 2 \text { for the categorization of clinical activities. } \\
\text { b No restrictions recommended, so long as the infected healthcare provider (1) is not detected as having } \\
\text { transmitted infection to patients; (2) obtains advice from an Expert Review Panel about continued practice; } \\
\text { (3) undergoes follow-up routinely by Occupational Medicine staff (or an appropriate public health official), } \\
\text { who test the provider twice per year to demonstrate the maintenance of a viral burden of less than the } \\
\text { recommended threshold (see text); (4) also receives follow-up by a personal physician who has expertise in } \\
\text { the management of her or his infection and who is allowed by the provider to communicate with the Expert } \\
\text { Review Panel about the provider's clinical status; (5) consults with an expert about optimal infection control } \\
\text { procedures (and strictly adheres to the recommended procedures, including the routine use of double-gloving } \\
\text { for Category II and Category III procedures and frequent glove changes during procedures, particularly if } \\
\text { performing technical tasks known to compromise glove integrity [eg, placing sternal wires]), and (6) agrees } \\
\text { to the information in and signs a contract or letter from the Expert Review Panel that characterizes her or } \\
\text { his responsibilities (see text). }\end{array}$} \\
\hline
\end{tabular}

if performing technical tasks known to compromise glove integrity [eg, placing sternal wires]); (6) agrees to the information in and signs a contract or letter from the Expert Review Panel that characterizes her or his responsibilities (discussed in more detail in Recommendation 8, below).

\section{$\mathrm{HCV}$}

SHEA recommends that $\mathrm{HCV}$-infected providers who have circulating HCV viral burdens of greater than or equal to $10^{4}$ $\mathrm{GE} / \mathrm{mL}$ routinely use double-gloving for all invasive procedures, for all contact with mucous membranes or nonintact skin, and for all instances in patient care for which gloving is routinely recommended, and that they not perform those Category III activities identified as associated with a risk for provider-to-patient transmission of bloodborne pathogen infection despite the use of appropriate infection control procedures. SHEA also recommends that an HCV-infected provider who has a viral burden of less than $10^{4} \mathrm{GE} / \mathrm{mL}$ not be excluded from any aspect of patient care, including the performance of Category III procedures (Tables 1 and 2), so long as the infected provider (1) is not detected as having transmitted infection to patients; (2) obtains advice from an Expert
Review Panel about continued practice; (3) undergoes followup routinely by Occupational Medicine, who tests the provider twice annually to demonstrate the maintenance of a viral burden of less than $10^{4} \mathrm{GE} / \mathrm{mL}$; (4) also receives followup by a personal physician who has expertise in the management of HCV infection and who is allowed by the provider to communicate with the Expert Review Panel about the provider's clinical status; (5) consults with an infection control expert about optimal infection control procedures (and strictly adheres to the recommended procedures, including the routine use of double-gloving during Category II and Category III procedures and frequent glove changes during procedures, particularly if performing technical tasks known to compromise glove integrity [eg, placing sternal wires]); 6) agrees to the information in and signs a contract or letter from the Expert Review Panel that characterizes her or his responsibilities (discussed in more detail in Recommendation 8, below).

\section{HIV}

SHEA recommends that HIV-infected providers who have circulating HIV viral burdens of greater than or equal to 
$5 \times 10^{2} \mathrm{GE} / \mathrm{mL}$ routinely use double-gloving for all invasive procedures, for all contact with mucous membranes or nonintact skin, and for all instances in patient care for which gloving is recommended, and that they not perform those Category III activities identified as associated with a risk for provider-to-patient transmission of bloodborne pathogen infection despite the use of appropriate infection control procedures (Tables 1 and 2). SHEA recommends that an HIVinfected provider who has a viral burden of less than $5 \times$ $10^{2} \mathrm{GE} / \mathrm{mL}$ not be excluded from any aspect of patient care, including the performance of Category III procedures, so long as the infected provider (1) is not detected as having transmitted infection to patients; (2) obtains advice from an Expert Review Panel about continued practice; (3) undergoes followup routinely by Occupational Medicine (or an appropriate public health official), who tests the provider twice annually to demonstrate the maintenance of a viral burden of less than $5 \times 10^{2} \mathrm{GE} / \mathrm{mL}$; (4) also receives follow-up by a personal physician who has expertise in the management of HIV infection and who is allowed by the provider to communicate with the Expert Review Panel about the provider's clinical status; (5) consults with an expert about optimal infection control procedures (and strictly adheres to the recommended procedures, including the routine use of double-gloving for Category II and Category III procedures and frequent glove changes during procedures, particularly if performing technical tasks known to compromise glove integrity [eg, placing sternal wires]); and (6) agrees to the information in and signs a contract or letter from the Expert Review Panel that characterizes her or his responsibilities (discussed in more detail in Recommendation 8, below).

\section{General Recommendations}

The rationale for these recommendations is presented below (in the section Background and Rationale). SHEA argues for comprehensive education concerning bloodborne pathogens for all healthcare providers and trainees. SHEA recommends managing infected providers in the context of a comprehensive approach to the management of all impaired providers. SHEA emphasizes the importance of patient safety as well as provider privacy and medical confidentiality. The Society also emphasizes the importance of offering employees who have disabilities reasonable accommodation for their disabilities. The guideline discusses exposure management in detail and, in general, recommends adherence to existing guidelines for managing exposures to these viruses. SHEA underscores that practitioners who are institutionally based and who develop one of these bloodborne pathogen infections are ethically bound to report their infections to their institutions' occupational medicine providers and to engage in the processes outlined below. Further, practitioners who are not institutionally based and who develop one of these bloodborne pathogen infections are ethically bound to engage their public health departments (consonant with state and local laws), as described below. Finally, the society encourages routine voluntary, confidential testing of providers, emphasizing that providers who conduct Category III procedures should know their immune or infection status with respect to each of these 3 bloodborne pathogens. Specific details and the rationale for these recommendations are included in the body of the guideline.

\section{INTRODUCTION}

In 1990, in response to public and professional concern that arose in the wake of a highly publicized cluster of cases of provider-to-patient transmission of the human immunodeficiency virus (HIV) in a Florida dentist's practice, ${ }^{3-8,}$ SHEA, in collaboration with the Association for Practitioners in Infection Control, published a position paper concerning the administrative management of healthcare providers who are infected with certain bloodborne pathogens. ${ }^{9}$ As additional information became available, in 1997 SHEA issued an updated position paper discussing the management of healthcare workers infected with hepatitis B virus (HBV), hepatitis C virus (HCV), HIV, or other bloodborne pathogens. ${ }^{10}$ The purpose of the present guideline is to provide updated guidance from SHEA regarding the administrative management of providers infected with these bloodborne pathogens, given the progress in the field since 1997.

Despite the widespread use of the hepatitis B vaccine, HBV remains the most commonly transmitted bloodborne pathogen in the healthcare setting. Although continued widespread administration of the vaccine should eventually mitigate this risk, any guideline for the years 2009 and beyond must include recommendations for HBV-infected providers. Similarly, the past 12 years' experience has provided insight in the factors influencing the risk for provider-to-patient transmission of HCV. Because we do not have a hepatitis C vaccine yet, and, with the prevalence of HCV infection rising around the world, this flavivirus is likely to become the most frequently transmitted bloodborne pathogen in health care in the years ahead. Provider-to-patient transmission of HIV has been extremely rare, with no cases reported worldwide since 2003. Nonetheless, the first instance of transmission of HIV from an infected provider to a patient was the driving force for the creation of guidelines and recommendations about providers infected with bloodborne pathogens.

This document provides updated information about each virus and the healthcare risks associated with infected practitioners and then addresses a series of questions relevant to the management of providers infected with each of these viruses. We then make recommendations about the management of providers infected with these bloodborne pathogens, citing the available evidence supporting the recommendations. The evidence base for these recommendations is limited at best. By the very nature of the topics being discussed, direct hypothesis-driven experimentation is virtually impossible, and may be complicated further by a low rate of voluntary 
TABLE 2. Categorization of Healthcare-Associated Procedures According to Level of Risk for Bloodborne Pathogen Transmission

Category I: Procedures with de minimis risk of bloodborne virus transmission

- Regular history-taking and/or physical or dental examinations, including gloved oral examination with a mirror and/or tongue depressor and/or dental explorer and periodontal probe

- Routine dental preventive procedures (eg, application of sealants or topical fluoride or administration of prophylaxis ${ }^{a}$ ), diagnostic procedures, orthodontic procedures, prosthetic procedures (eg, denture fabrication), cosmetic procedures (eg, bleaching) not requiring local anesthesia

- Routine rectal or vaginal examination

- Minor surface suturing

- Elective peripheral phlebotomy ${ }^{\mathrm{b}}$

- Lower gastrointestinal tract endoscopic examinations and procedures, such as sigmoidoscopy and colonoscopy

- Hands-off supervision during surgical procedures and computer-aided remote or robotic surgical procedures

- Psychiatric evaluations ${ }^{c}$

Category II: Procedures for which bloodborne virus transmission is theoretically possible but unlikely

- Locally anesthetized ophthalmologic surgery

- Locally anesthetized operative, prosthetic, and endodontic dental procedures

- Periodontal scaling and root planing ${ }^{\mathrm{d}}$

- Minor oral surgical procedures (eg, simple tooth extraction [ie, not requiring excess force], soft tissue flap or sectioning, minor soft tissue biopsy, or incision and drainage of an accessible abscess)

- Minor local procedures (eg, skin excision, abscess drainage, biopsy, and use of laser) under local anesthesia (often under bloodless conditions)

- Percutaneous cardiac procedures (eg, angiography and catheterization)

- Percutaneous and other minor orthopedic procedures

- Subcutaneous pacemaker implantation

- Bronchoscopy

- Insertion and maintenance of epidural and spinal anesthesia lines

- Minor gynecological procedures (eg, dilatation and curettage, suction abortion, colposcopy, insertion and removal of contraceptive devices and implants, and collection of ova)

- Male urological procedures (excluding transabdominal intrapelvic procedures)

- Upper gastrointestinal tract endoscopic procedures

- Minor vascular procedures (eg, embolectomy and vein stripping)

- Amputations, including major limbs (eg, hemipelvectomy and amputation of legs or arms) and minor amputations (eg, amputations of fingers, toes, hands, or feet)

- Breast augmentation or reduction

- Minimum-exposure plastic surgical procedures (eg, liposuction, minor skin resection for reshaping, face lift, brow lift, blepharoplasty, and otoplasty)

- Total and subtotal thyroidectomy and/or biopsy

- Endoscopic ear, nose, and throat surgery and simple ear and nasal procedures (eg, stapedectomy or stapedotomy, and insertion of tympanostomy tubes)

- Ophthalmic surgery

- Assistance with an uncomplicated vaginal delivery

- Laparoscopic procedures

- Thoracoscopic procedures ${ }^{\mathrm{f}}$

- Nasal endoscopic procedures ${ }^{g}$

- Routine arthroscopic procedures ${ }^{\mathrm{h}}$

- Plastic surgery

- Insertion of, maintenance of, and drug administration into arterial and central venous lines

- Endotracheal intubation and use of laryngeal mask

- Obtainment and use of venous and arterial access devices that occur under complete antiseptic technique, using universal precautions, "no-sharp" technique, and newly gloved hands

Category III: Procedures for which there is definite risk of bloodborne virus transmission or that have been classified previously as "exposure-prone"

- General surgery, including nephrectomy, small bowel resection, cholecystectomy, subtotal thyroidectomy other elective open abdominal surgery

- General oral surgery, including surgical extractions, ${ }^{j}$ hard and soft tissue biopsy (if more extensive and/or having difficult access for suturing), apicoectomy, root amputation, gingivectomy, periodontal curettage, mucogingival and osseous surgery, alveoplasty or alveoectomy, and endosseous implant surgery 


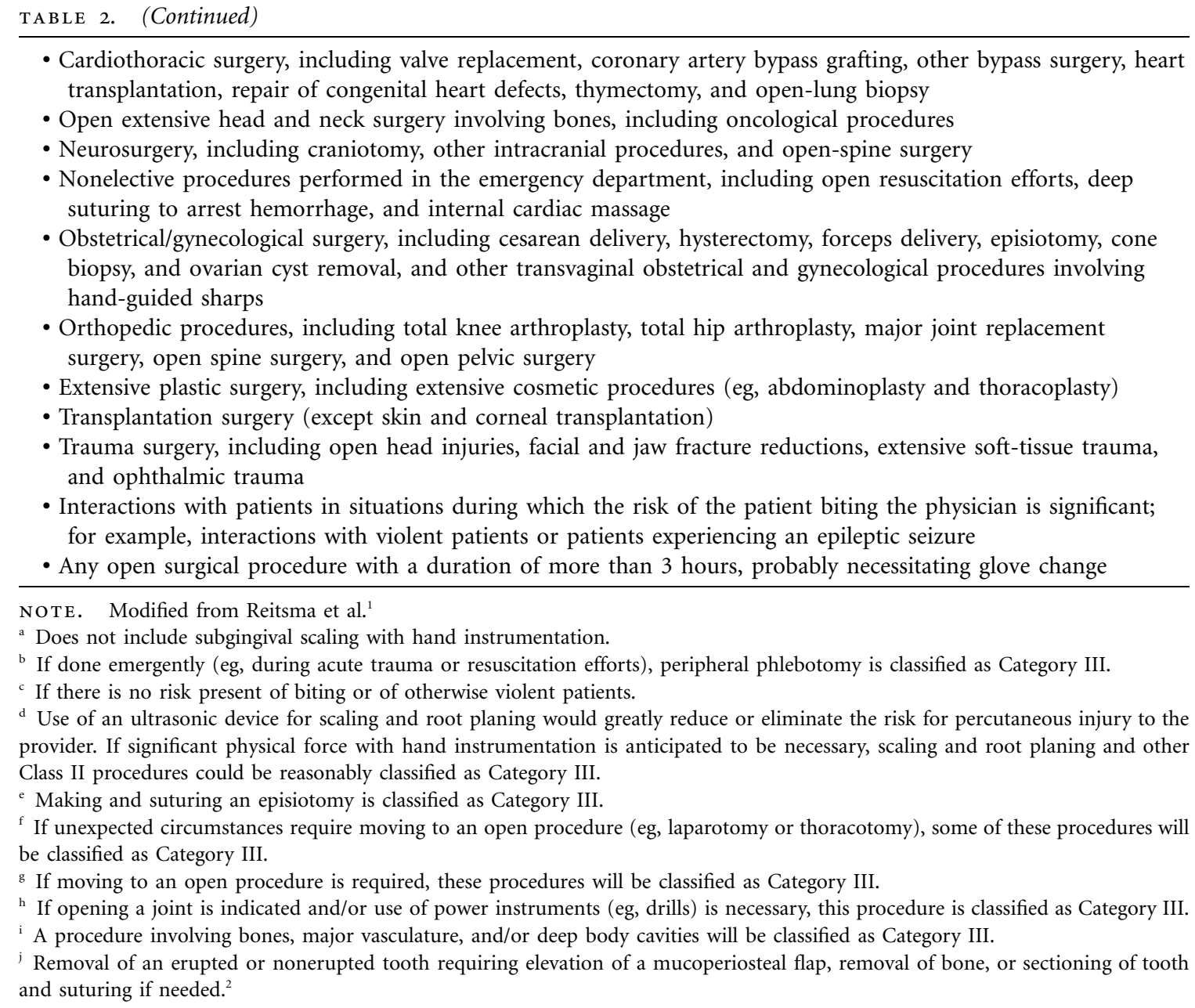

reporting of both infection status and high-risk provider-topatient transmission events. Most data that we have about this subject come from documented instances of transmission. Many if not most of the conclusions from these studies are inferential. Some evidence comes from experimental laboratory studies or models. Thus, this guideline cannot have the scientific evidence-base found in many other guidelines. Nonetheless, we do have a broad experience working with these pathogens in the healthcare setting and the science base is much more robust than it was at the time the last guidance was published by SHEA in 1997.

\section{E P I D E M I O L O GY}

\section{Provider-to-Patient Transmission of HBV}

With respect to HBV transmission, through 1994, investigators at the Centers for Disease Control and Prevention (CDC) had identified 42 instances of provider-to-patient transmission of HBV (375 patients). ${ }^{11}$ Subsequently, 2 additional clusters of provider-to-patient transmission of $\mathrm{HBV}$ infection were reported that involved surgeons who tested positive for HBeAg. ${ }^{12,13}$

In one of these more recent clusters, 4 patients acquired clinical hepatitis B infection from an orthopedic surgeon following surgeries conducted by the infected provider. ${ }^{13}$ In a second, more recent cluster, 19 of the 144 susceptible patients whose surgical team included an HBV-infected thoracic surgery resident became infected. ${ }^{12}$ No specific events or breaks in technique were identified in either cluster that could explain the transmissions, although the thoracic surgery resident did not wear double gloves. Since 1996, there have been an additional 10 reports of hepatitis B transmission from providers to patients. These cases have generally been associated with $\mathrm{HBV}$-infected surgeons; one case was associated with an infected dentist ${ }^{14,15}$ (I. Williams, CDC, personal communication). An important report from the United Kingdom underscored the potential for transmission from providers who are infected with so-called "pre-core" mutants of HBV. ${ }^{14}$ Such providers are HBeAg negative but have a high circulating viral burden. This report ${ }^{14}$ underscores the importance of directly measuring viral burden, as opposed to assaying for surrogate markers of viral burden (such as HBeAg). Only one relatively recent report is from North America: in this large outbreak, 75 patients were infected from procedures involving placement of subdermal electroencephalogram electrodes by 
an HBeAg-positive technician. ${ }^{16}$ Although infection control procedures in this electroencephalography clinic were deemed inadequate, no specific mechanism for transmission was identified.

Although such clusters continue to occur (acknowledging that the United States does not have systemic surveillance measures to detect such cases), they appear to be occurring less frequently than in the past. In contrast, the problem of patient-to-patient transmission of $\mathrm{HBV}$ and $\mathrm{HCV}$ arising from inadequate infection control precautions, such as reuse of multidose vials of medication, has become increasingly important as a cause of iatrogenic bloodborne pathogen infection. ${ }^{17}$

\section{Provider-to-Patient Transmission of $\mathrm{HCV}$}

Provider-to-patient transmission of HCV has been extremely uncommon in the United States and has had a reasonably unique epidemiology in this county. Conversely, transmission of HCV from infected providers has been somewhat more frequently detected in Europe (Table 3). As noted above, for all of these pathogens, provider-to-patient transmission of $\mathrm{HCV}$ is extremely unlikely in the course of routine (ie, noninvasive) patient care. The risk for provider-to-patient transmission of HCV appears to be even smaller than the risk for $\mathrm{HBV}$ transmission in the course of noninvasive patient care, presumably because most individuals chronically infected with HCV have circulating viral loads that are orders of magnitude lower than those of the hepatitis B carriers who have been identified as transmitting infection to their patients.

Several instances of provider-to-patient transmission of $\mathrm{HCV}$ have been reported in the literature. ${ }^{18-32}$ The first documented instance of provider-to-patient transmission of HCV was reported from England in 1995 (Table 3). ${ }^{23}$ A patient who had undergone cardiac surgery developed acute $\mathrm{HCV}$ infection and had no risk factors for infection. The first assistant surgeon on the operative team was found to be infected with HCV. A "look-back" study of the patients for whom the surgeon had provided care revealed that only one of the surgeon's 278 patients developed HCV infection with a strain identical to the surgeon's. ${ }^{21}$ During the time the UK investigation was in process, an additional instance of provider-to-patient transmission of $\mathrm{HCV}$ was reported from Spain. ${ }^{22}$ The detection of 2 unexpected cases of HCV infection among cardiac surgery patients participating in a study of transfusion-transmitted infections prompted a look-back study of the patients of a chronically HCV-infected surgeon. The Spanish look-back study identified an additional $4 \mathrm{HCV}$ infections (ie, totaling 6 [2.7\%] of the 222 patients who had been operated on by the surgeon). ${ }^{22}$ Five of the $6 \mathrm{HCV}$ strains isolated from these patients were closely related to the strain

TABLE 3. Summary of Reports of Provider-to-Patient Hepatitis C Virus Transmission from the United Kingdom

\begin{tabular}{|c|c|c|c|c|c|}
\hline Year & $\begin{array}{l}\text { Provider's } \\
\text { occupation }\end{array}$ & Procedure & $\begin{array}{l}\text { No. of } \\
\text { patients } \\
\text { tested }\end{array}$ & $\begin{array}{c}\text { No. of } \\
\text { probable } \\
\text { cases }\end{array}$ & $\begin{array}{c}\text { Transmission rate, } \\
\%(95 \% \mathrm{CI})\end{array}$ \\
\hline 1995 & $\begin{array}{l}\text { Cardiovascular } \\
\text { surgery }\end{array}$ & $\begin{array}{l}\text { Coronary artery } \\
\text { bypass }\end{array}$ & $270^{a}$ & 1 & $0.37(0.00-1.44)$ \\
\hline 1999 & Gynecology & $\begin{array}{l}\text { Gynecological } \\
\text { procedure }\end{array}$ & $3,628^{\mathrm{b}}$ & 7 & $0.19(0.08-0.36)$ \\
\hline 2000 & General surgery & Bowel surgery & $627^{c}$ & 2 & $0.32(0.03-0.91)$ \\
\hline 2000 & General surgery & Bowel surgery & $1,145^{\mathrm{d}}$ & 4 & $0.35(0.09-0.77)$ \\
\hline 2001 & Obstetrics & Cesarean delivery & $198^{\mathrm{e}}$ & 1 & $0.51(0.00-1.97)$ \\
\hline 2002 & $\begin{array}{c}\text { Obstetrics and } \\
\text { gynecology }\end{array}$ & Cesarean delivery & $\begin{array}{l}\text { Investigation } \\
\text { ongoing }\end{array}$ & $\begin{array}{l}\text { Investigation } \\
\text { ongoing }\end{array}$ & $\begin{array}{l}\text { Investigation } \\
\text { ongoing }\end{array}$ \\
\hline 2004 & $\begin{array}{l}\text { Obstetrics and } \\
\text { gynecology }\end{array}$ & Cesarean delivery & $\begin{array}{l}\text { Investigation } \\
\text { ongoing }\end{array}$ & $\begin{array}{c}\text { Investigation } \\
\text { ongoing }\end{array}$ & $\begin{array}{l}\text { Investigation } \\
\text { ongoing }\end{array}$ \\
\hline Overall & $\ldots$ & $\ldots$ & 5,868 & 15 & $0.26(0.13-0.38)$ \\
\hline
\end{tabular}

note. Data provided by Fortune Ncube, MD, Health Protection Agency Centre for Infections, United Kingdom (personal communication). CI, confidence interval.

${ }^{a}$ More than $97 \%$ of the procedures (ie, procedures in 270 of 278 patients) that the provider had participated in were classified by the incident team as "high-risk exposure-prone procedures."

b Patient notification was performed in 2 stages: the identification of 4 transmissions triggered an extension of the look-back exercise, resulting in the identification of 3 additional infections.

c All the patients included in the analysis had procedures that met investigators' definition of "high risk exposureprone procedures," and $84 \%$ (627 of 750) of the infected provider's exposure-prone procedures were characterized as "high risk exposure-prone procedures."

d All these patients had undergone exposure-prone procedures. Investigators assumed that this general surgeon's workload was similar to that of the other general surgeon (ie, $84 \%$ of exposure prone procedures were "high-risk exposure prone procedures").

' All the patients tested and included in the table (ie, accounting for 198 of 228 of the provider's procedures) were patients who had high "high risk exposure-prone procedures." 
isolated from the surgeon, and each of these patients had undergone valve replacement surgery. ${ }^{22}$

An HCV-infected gynecologist in the UK transmitted infection to several patients. After a single patient became infected after a gynecological procedure, ${ }^{24,33}$ a detailed lookback study tested more than 4,500 patients, of whom 3,628 had undergone "high risk, exposure-prone procedures" that were performed by the surgeon in the previous 20 years. Seven additional patients were found to have $\mathrm{HCV}$ infection caused by strains of HCV closely related to the strain recovered from the surgeon (Table 3). ${ }^{26}$

Ross and coworkers ${ }^{28}$ from Germany reported the results of a look-back study of 207 of the 229 patients operated on by an HCV-infected orthopedic surgeon. Three of the 207 were found to be HCV infected, but only 1 (a patient who had undergone a total hip arthroplasty with trochanteric osteotomy) was infected with a strain that was similar to the strain recovered from the HCV-infected orthopedist. ${ }^{28}$ Subsequently, these same investigators also conducted a lookback study of the patients of an HCV-infected obstetrician/ gynecologist. The look-back study was prompted by the detection of an unanticipated instance of HCV infection in a patient who had undergone a cesarean delivery. This patient was found to be infected with an HCV strain that was virtually identical to the strain infecting the obstetrician/gynecologist who had performed the procedure. ${ }^{29}$ The investigators screened 2,286 of the obstetrician/gynecologist's 2,907 patients and found no further evidence of transmission. ${ }^{29}$

Three additional patient-to-provider look-back studies involving the potential for transmission of HCV from healthcare worker to patient have been reported from the United Kingdom (Table 3). ${ }^{27,34,35}$ In the first of these studies, 3 infections (among 1,900 patients) were attributed to an HCVinfected provider. In the second, 1 infection was found among 749 patients of an HCV-infected provider. ${ }^{35}$ In the third, a look-back study has been reported as being initiated in the United Kingdom, although no results from the study have been published $;^{27}$ letters were sent to 228 patients of an HCVinfected practitioner offering follow-up testing, after an index case was identified as linked to the practitioner following an "exposure-prone" procedure.

Several reports involve HCV-infected anesthesiologists. In the United Kingdom, ${ }^{31}$ an HCV-infected anesthesiologist infected a patient during a procedure in which the anesthesiologist endotracheally intubated the patient, inserted a peripheral venous catheter, and provided general anesthesia. He did not participate in any procedure considered to be "exposure-prone." The anesthesiologist vehemently denied injection drug use $\mathrm{e}^{31}$; however, in several similar cases described below, drug diversion was implicated as the cause of bloodborne pathogen transmission.

Ross and colleagues ${ }^{36}$ reported a cluster of 5 cases of HCV infection from an anesthesia assistant. The anesthesia assistant purportedly acquired acute HCV infection as a result of an occupational exposure to an $\mathrm{HCV}$-infected patient in the op- erating room (presumably, by contaminating an open wound on a finger of his right hand). This assistant may have presented an increased risk for transmission, since he was working while developing acute HCV infection and before having a detectable immunologic response at a time when his viral burden was likely high. In the course of 3 weeks (during which his finger was purportedly still weeping) he infected 5 patients. He vehemently denied drug abuse, but the similarity of this case to the case described by Sehulster and colleagues ${ }^{37}$ (discussed below) is striking. An important feature of this cluster is the fact that the anesthesia assistant did not follow universal/standard precautions. He did not wear gloves (even when he had the open lesion on his right hand). Ross and colleagues $^{36}$ suggest that if the anesthesia assistant had followed universal/standard precautions, these infections would have likely been prevented.

In another highly unusual case, a child acquired HCV infection from his mother, who was functioning as his healthcare provider. ${ }^{38}$ The child was a hemophiliac whose mother administered his frequently required clotting-factor concentrate infusions. The mother (who had chronic HCV infection) did not wear gloves and recalled several instances in which she stuck her own finger with the needle (often with her own blood visible). Sequence analysis demonstrated that the HCV isolates from the mother and the child were identical. ${ }^{38}$

For reasons that are not certain, look-back studies from the United Kingdom have found substantially more cases of transmission. Grouping the various studies from the United Kingdom yields a transmission rate of $0.19 \%$ (15 patients infected of 7,656 patients tested) without inclusion of index cases, and $0.26 \%$ with the inclusion of index cases. In contrast, studies from Germany have found no additional cases of transmission among more than 3,000 people tested, beyond the index cases that prompted the look-back studies. However, if one includes the index cases, the transmission rate for these studies is $0.13 \%$ (similar to the rate for the studies from the United Kingdom).

The experience in the United States is quite different. Injection drug use on the part of the infected provider appears to play a more central role in provider-to-patient HCV transmission. Williams and colleagues ${ }^{39}$ recently reviewed the US experience, noting that 4 episodes of transmission have been detected. The first involved an HCV-infected surgical technician who infected approximately 40 of 346 patients during a 3-month period. ${ }^{37,39}$ This healthcare provider admitted selfinjecting anesthesia medications and then using the same syringe to administer drugs to patients. The second involved an anesthesiologist who acquired HCV infection from one patient and subsequently, during the anesthesiologist's acute phase of infection, transmitted the same strain of HCV to a patient; no further transmissions were identified. This anesthesiologist was also suspected to be abusing narcotics. ${ }^{20,39}$ The third case of HCV transmission is more similar to those seen in the United Kingdom. An HCV-infected cardiac surgeon was found to have infected as many as 14 of the 937 
patients who could be evaluated from over a decade of surgical practice. ${ }^{39}$ Narcotics abuse was not suspected. Interestingly, following an expert review of the surgeon's practice, the surgeon was treated for his HCV infection and was allowed to continue to practice; he continued to perform cardiovascular procedures that would by any measure be considered exposure-prone. He made modifications to his technique, including the use of double gloves and other safety devices, and in addition, his patients were prospectively tested for HCV infection; to date no additional instances of transmission have been detected. The fourth report describes a certified registered nurse anesthetist who transmitted HCV to at least 15 of 164 patients during a 4-month period coinciding with the acute phase of his own HCV infection. The certified registered nurse anesthetist did not perform exposure-prone procedures and a specific mechanism of transmission was not identified; however, similar to the first 2 cases, the nurse anesthetist was suspected of abusing patient medications. ${ }^{39} \mathrm{~A}$ fifth instance of provider-to-patient transmission of HCV in the United States is currently under investigation, but the details are not yet available (J. Perz, CDC, personal communication).

Although the precise mode of transmission for $\mathrm{HCV}$ for the majority of these cases remains unknown, the circumstances surrounding several of the cases suggest that transmission was associated with percutaneous exposures. Clearly, at least in the United States, a number of the instances of provider-to-patient HCV transmission have been associated with diversion of patients' drugs to healthcare providers who were abusing injectable narcotics. Although the contribution of injection drug use to provider-to-patient transmission of HCV has been most noticeable in the United States, 2 additional cases, one from Spain, the other from Israel, underscore its potential importance. In the cluster of cases from Spain, an anesthesiologist who was addicted to opiates was diverting some of patients' narcotics for personal use and then injecting the patients with the same syringe that he had used, thereby infecting more than 200 patients. ${ }^{18,40}$ In the report from Israel, an injection drug-using anesthesiologist infected 33 patients by diverting some patients' drugs to himself and then using the same apparatus for injecting the drugs into the patient. ${ }^{32}$ Detection of underlying injection drug use in these circumstances is difficult, at best, so one cannot say for certain the extent to which this behavior may have influenced the other cases reported in the literature.

Summarizing the world literature and excluding those reports in which injection drug use was considered to be a contributing factor for transmission, there were 2 gynecologists, 3 cardiac or thoracic surgeons, 1 anesthesiologist, and 1 orthopedic surgeon involved in the instances of transmission. These data lend credence to the hypothesis that "exposure-prone, invasive procedures" are likely to pose the largest risk for provider-to-patient transmission of HCV.

\section{Provider-to-Patient Transmission of HIV}

In the 25 years since HIV was first isolated, only 4 instances of HIV transmission from infected health care workers to 1 or more patients have been reported. ${ }^{3-8,41-45}$ One cluster of infections occurred in the United States in $19903^{3-8} 2$ cases occurred in France, ${ }^{41,42,44,45}$ and 1 instance of transmission occurred in Spain. ${ }^{43}$

The US cluster involved a dentist who had acquire immune deficiency syndrome (AIDS); 6 of his patients became HIV infected. Their HIV isolates were linked to his, both epidemiologically and by DNA sequencing. ${ }^{3-8}$ A thorough investigation by the CDC and viral phylogeny findings suggested practitioner-to-patient spread, though the precise mechanism or mechanisms of transmission were not determined. Although the dentist was a patient in his own practice, no infection control deficiencies were identified that would readily explain HIV transmission to the 6 patients. Additionally, the dentist did not recall occupational injuries that could have created an opportunity for cross-contamination. Despite substantial speculation, no data were uncovered suggesting intentional transmission.

The second instance of provider-to-patient HIV transmission involved an orthopedic surgeon in France who transmitted HIV to 1 patient. Transmission was confirmed through DNA sequence analysis of viral isolates obtained from the surgeon and the patient. ${ }^{42,45}$ The surgeon was not aware of his infection until surveillance case definition AIDS was diagnosed. French investigators initiated a look-back study of the surgeon's 3004 patients since 1983. Investigators successfully contacted 2458 patients and performed HIV serologic tests on 983. One patient was found to have acquired HIV infection. This patient had 3 procedures performed by the surgeon, had a negative HIV serology before undergoing the first of the 3 procedures, and was found to be infected with HIV when she underwent testing before the third procedure. ${ }^{42,45}$ The authors of the manuscript speculated that both the extended length of the initial procedure (10 hours) and the high likelihood that the surgeon had a high viral burden (since he had far advanced, untreated disease) contributed to the transmission. No breaches in recommended infection-control practices were identified in retrospect.

The third episode of provider-to-patient HIV transmission also was detected in France. In this unusual case, transmission of HIV is suggested to have occurred from an infected nurse to a patient, although no clear mechanism for transmission could be identified. ${ }^{44}$ The investigators conducted a look-back study focusing on 7,580 patients for whom the infected nurse had provided care. They were able to locate 5,308 patients, and they serologically tested $2,293 .{ }^{41}$ No additional infections were identified. The nurse was coinfected with HCV and had both a high HIV viral burden and advanced HCV-induced hepatic disease, including clotting abnormalities. HCV was apparently not transmitted to the patient, but the HIV isolates from patient and provider were closely related. The nurse was 
unaware of either viral infection, though she became symptomatic enough to require hospitalization within 2 weeks of the date on which transmission was thought to have occurred. She denied injection drug use.

The fourth case occurred in Spain; a woman was infected with HIV by her obstetrician/gynecologist during cesarean delivery. Spanish officials conducted a look-back evaluation of the physician's patients. Of 275 patients on whom the practitioner had performed procedures, 250 could be tested, and none were found to be infected. ${ }^{43}$

More than 4 dozen look-back studies have been conducted evaluating the HIV antibody status of patients retrospectively identified as having received medical or dental care from an HIV-infected practitioner ${ }^{5,46-57}$ (Lisa Panlilio, CDC, personal communication). None of these studies identified transmission of HIV infection. To our knowledge, only the report from France described above, in which an orthopedic surgeon infected one of his patients, identified iatrogenic transmission of HIV in a look-back study. ${ }^{42,45}$ In the United Kingdom, no cases of HIV transmission from a healthcare worker to a patient have been detected, despite 28 patient notification exercises and testing of more than 11,000 patients between 1988 and 2006 (F. Ncube, MD, Health Protection Agency Centre for Infections, United Kingdom, personal communication). One unusual cluster of patient-to-patient HIV transmission in a surgical practice in Australia has been described in the literature ${ }^{58}$ however, the practitioner providing the care was not infected.

\section{PATHOGENESIS AND TRANSMISSION RISK}

HBV, HCV, and HIV are most readily transmitted either parenterally or across mucous membranes. Therefore, experts uniformly agree that the risk for transmission of these viruses from an infected provider to a patient during the provision of routine healthcare that does not involve invasive procedures is negligible. In instances in which invasive procedures, and even exposure-prone invasive procedures, are being conducted, these risks are still quite small, but are clearly elevated when compared with other routine patient-care activities. For this reason, a precise assessment of the magnitude of risk for transmission of each of the viruses-in the context of procedures associated with risks for exposing patients to the infected provider's blood or virus-containing body fluidsbecomes critical to the overall risk assessment. At least in part because these transmission events occur uncommonly for each of these 3 pathogens, such information is difficult to accumulate.

Several studies have attempted to measure the risk that is associated with single discrete exposures (eg, the "needlestick" transmission rate) for transmission of these 3 pathogens. Only a few manuscripts have addressed the risk to patients who are cared for by an HBV-infected practitioner, ${ }^{11,14,59-63}$ an HCV-infected practitioner, ${ }^{22,23,64-66}$ or an HIV-infected prac- titioner ${ }^{5,46-51,54,57,67}$ Several variables are likely to influence the transmission rate.

The first factor to influence risk is the intrinsic transmissibility of a specific pathogen. With respect to HBV, studies from the 1970s and 1980s demonstrated a risk for transmission associated with a percutaneous (ie, needlestick) exposure to blood from an HBV-infected individual that ranged from $6 \%$ to $37 \%$ (19\%-37\%, if the donor blood is HBeAg-positive) ${ }^{68,69}$ The risk for transmission of $\mathrm{HCV}$ associated with such exposures has been estimated at 1\%-2\% (summarized in Henderson ${ }^{65}$ ). The risk for transmission of HIV associated with needlestick or percutaneous exposures has been estimated at $0.3 \%$ (summarized in Henderson ${ }^{70}$ ). With the exception of the HBV studies (which do make the distinction between $\mathrm{HBeAg}$-positive and $\mathrm{HBeAg}$-negative source patients), none of the HCV or HIV transmission studies considers the circulating viral burden of the source patient in the risk calculation.

With respect to HIV transmission from provider to patient, since the previous version of this guideline ${ }^{10}$ was published in 1997, only 3 instances of transmission have been detected, ${ }^{41-45}$ and in each instance only 1 patient was found to be infected, despite exhaustive look-back investigations.

A second important issue for consideration in assessing the risk for provider-to-patient transmission of bloodborne pathogens is the frequency with which providers sustain injuries that might present a risk for transmission to their patients. ${ }^{71-79}$ Since the previous version of this guideline ${ }^{10}$ was published, numerous strategies and interventions designed to reduce the risk for occupational exposures for providers have been implemented (discussed in more detail in the later part of this section). Many of these interventions have been shown to be efficacious in reducing risks for occupational exposures; ${ }^{80-86}$ however, in many instances, the use of such interventions has been suboptimal. ${ }^{87-89}$ Another set of factors that relates directly to the frequency with which exposures occur includes both the experience of the practitioner and the expertise of the practitioner. With respect to experience, clearly, students and trainees are more likely to sustain such exposures. A special problem arises when a training institution becomes aware that a trainee is chronically infected with a bloodborne pathogen. Such instances should be handled on a case-bycase basis, in consultation with the institution's legal counsel, the house staff training director, infection control professionals, the dean of the school, and others who are involved stakeholders. To date, these cases have been handled unevenly across the country, with some institutions focusing on the disability-law aspects and others focusing on liability. ${ }^{90}$ The institution should assist the trainee in selecting a career path best suited to her or his specific situation and should provide reasonable accommodation to students and trainees who have disabling conditions. The expertise of the practitioner is more complex to measure, but may be indirectly assessed by evaluating postprocedure infection rates, bleeding and other pro- 
cedure-related complications, and other adverse events associated with the performance of the practitioner.

The third issue that warrants consideration is how frequently such an exposure occurs and is then followed by exposure to a patient (ie, the so-called "recontact" or "bleedback" risk). For example, intraoperative injuries sustained by surgical care providers offer an opportunity for "recontact" to occur. In 2 studies of intraoperative provider injuries, $11.4 \%-29 \%$ of the sharp objects that caused injury to the provider "recontacted" the patient. ${ }^{73,79}$ These exposures can be prevented by immediately replacing the contaminated suture needle or other sharp object before reuse. Recontacts can also occur when the provider is injured by bone spicules or materials permanently embedded in the patient's body. ${ }^{73,79}$ These sources of potential patient exposure might be prevented by the use of safety devices or other interventions. For example, such exposures might be prevented by the use of reinforced gloves, ${ }^{91,92}$ double-gloving, glove-liners, or other devices or materials to protect the provider's hands. ${ }^{89,91,93-96}$ Gloves constructed of monofilament polymers or other materials resistant to tears have become available for use when manipulation of bone fragments or suture wires is needed, but their use has been associated with a decrease in tactile sensation. In addition, the use of blunted suture needles has been shown to decrease the risk of percutaneous injuries to the surgeon. ${ }^{86,97-99}$

A fourth factor to consider in the risk assessment is the effect of the infected provider's circulating viral burden. However, with the exception of the HBV studies (which do make the distinction between $\mathrm{HBeAg}$-positive and $\mathrm{HBeAg}$-negative source patients), none of the HCV or HIV transmission studies considers the circulating viral burden of the source patient in the risk calculation, although the likelihood of HIV transmission is increased if a source case patient has advanced AIDS and, presumably, an elevated HIV viral load. For HBV, 5 studies have attempted to measure the viral burden of the provider associated with transmission of infection. In these studies, source case surgeons were found to have circulating HBV DNA levels between $6.4 \times 10^{4}$ and $5.0 \times 10^{9} \mathrm{GE} / \mathrm{mL}$. In a modeling study designed to assess the inoculum associated with the most common types of exposures, viral burdens equivalent to $10^{4} \mathrm{GE} / \mathrm{mL}$ or less were associated with exposures to fewer than 1 virion. ${ }^{100}$ An analysis of the technique used by one HBeAg-positive cardiovascular-thoracic surgeon implicated as the source of a cluster of HBV infections may shed some light on the risk for transmission associated with very high viral burdens. ${ }^{12,101}$ In this study, when the surgeon repeatedly tied knots, snugging them against his index finger, shear injuries occurred through his gloves, and both the saline irrigant used to rinse the inside of his gloves and the outer surface of the gloves tested positive for hepatitis B surface antigen ( $\mathrm{HBsAg}){ }^{12,101}$ Despite evidence suggesting a decreased risk for contamination with blood and/or body fluids associated with the practice of double-gloving, ${ }^{71}$ this surgeon did not wear 2 pairs of gloves-neither during clin- ical care nor for the experiments described above. Nonetheless, because of the extremely high viral burden associated with $\mathrm{HBeAg}$ positivity (100 million to 10 billion HBV particles per milliliter of blood) ${ }^{102}$ barriers may be relatively ineffective in preventing transmission, so the establishment of some cutoff value makes implicit sense.

A fifth issue to consider is the magnitude of risk of transmission of bloodborne pathogens following various types of exposures (summarized in Henderson ${ }^{70}$ ). For HIV, this risk has been studied extensively. The average risk of transmission associated with percutaneous exposures to blood-contaminated sharp objects that have been used on HIV-infected individuals is $0.32 \%$ (21 infections associated with $6,498 \mathrm{ex}$ posures; $95 \%$ confidence interval, $0.18 \%-0.46 \%$ ) (summarized in $\mathrm{Henderson}^{70}$ ). The risk for transmission of HBV from an HBeAg-positive source subject is approximately $2 \log _{10}$ higher; the likelihood of transmission of HCV from an HCVinfected source subject is intermediate, and is estimated to be approximately 10-fold less than that for HBV (ie, approximately $1 \%-2 \%$ per exposure) ${ }^{65}$ The estimated risk for transmission of HIV associated with mucocutaneous exposure is $0.03 \%$ ( 1 infection associated with 2,885 exposures), but this estimate is biased, because the single transmission occurred before prospective data were collected from the involved institution. ${ }^{103}$ The risk of infection associated with intact skin exposure to blood from an HIV-infected individual is below detection in the few studies that have attempted to measure it. ${ }^{104}$ Data estimating these latter risks are not available for either HBV or HCV, though one might reasonably assume that the risks might be higher for HCV and higher yet for HBV, given the numbers of cases infection detected for the hepatitis viruses, as well as the higher average circulating viral burdens in chronically infected individuals.

Because the risks for provider-to-patient transmission of these 3 bloodborne pathogens are apparently quite different (albeit there is a small risk for each of the 3 viruses), SHEA decided in the previous version of this guideline in 1997 to consider them individually. ${ }^{10}$ This updated version also follows that approach.

In 1991, the US Public Health Service published guidelines designed to prevent provider-to-patient transmission of HBV and HIV. ${ }^{105}$ Since that document was published, we have gained substantial insight into the factors that contribute to the risks for healthcare-associated transmission of these pathogens; we have witnessed substantial progress in the management of HBV, HCV, and HIV infection; we have seen the development of sensitive molecular tests designed to measure circulating viral burdens for these infections; and we have implemented a variety of interventional strategies designed to reduce these risks.

More than 20 infectious diseases have been transmitted by needlestick injuries. ${ }^{106}$ However, HBV, HCV, and HIV infections remain overwhelmingly the most important diseases to consider in provider-to-patient transmission. Other blood- 
borne diseases remain of hypothetical concern only. For this reason, this guideline will focus only on $\mathrm{HBV}, \mathrm{HCV}$, and HIV.

\section{CLINICAL PROGRESS SINCE PUBLICATION}

\section{OF THE 1997 SHEA GUIDELINE}

\section{HBV}

The previous version of this SHEA guideline ${ }^{10}$ relied on the presence of $\mathrm{HBeAg}$ as a surrogate marker of infectivity and did not consider direct measurement of the HBV DNA viral burden in making recommendations about practice restrictions. One major advance since the publication of the previous guideline is the recognition that presence of $\mathrm{HBeAg}$ is not a sensitive marker for HBV infectivity. Indeed, several instances of provider-to-patient transmission of HBV have involved providers who were infected with strains of HBV that did not produce HBeAg (so-called "pre-core" mutants). ${ }^{14,107}$ The use of HBeAg as a surrogate marker for infectivity has been effectively replaced by molecular tests that measure a patient's circulating viral burdens with precision. A third major advance is the availability of antiviral medications and other approaches to treat HBV infection. The past decade has seen the development of treatment strategies that, for the first time, offer some hope of reducing patients' viral burdens, and also of producing durable remissions, if not cures. The US Food and Drug Administration has approved 7 antiviral agents (interferon- $\alpha$, peg interferon, lamivudine, telbivudine, adefovir, tenofovir, and entecavir) for the treatment of chronic hepatitis B in the United States; others (eg, emtricitabine and clevudine) are currently under evaluation. Of patients who received monotherapy with one of the approved agents for 1 year, $14 \%-30 \%$ became negative for $\mathrm{HBeAg}$, and $21 \%-67 \%$ developed undetectable HBV DNA levels. ${ }^{108}$ The role of combination therapies is at too preliminary a stage to judge their efficacy; however, some studies have suggested that therapy with combinations of some of the newer nucleoside and nucleotide analogues (eg, truvada) are superior, or preferable, to monotherapy for patients who have HBeAg or high circulating levels of HBV DNA. ${ }^{108} \mathrm{Al}-$ though the evidence base for the use of antiviral and/or immunological therapy for hepatitis B is not yet fully adequate (ie, current therapy for chronic hepatitis B infection most often does not eradicate HBV and most studies demonstrate limited long-term efficacy), the role of therapy, the impact on the potential transmission risk, and the impact on practice restrictions have not yet been fully investigated.

\section{$\mathrm{HCV}$}

As is the case with HBV, in the past decade we have gained more sophistication and precision in our ability to measure the circulating viral burdens of patients infected with HCV. In addition, new antiviral agents and combinations of agents have been employed with increasing success to treat individuals who have acute and chronic HCV infection. A National
Institutes of Health Consensus Development Conference and 2 academic professional societies have published congruent treatment guidelines for individuals who are chronically infected with HCV. ${ }^{109-112}$ These guidelines emphasize that individuals who have chronic hepatitis $\mathrm{C}$ infection who are 18 years of age or older, have detectable HCV RNA in serum, and evidence of chronic hepatitis (either elevated serum alanine aminotransferase levels or active hepatitis and/or fibrosis) should be treated, assuming they are willing to participate in the therapy and that there are no contraindications to the use of the indicated antiviral agents. Also of importance are the several published studies that suggest that acute HCV infection can be treated with nearly $100 \%$ success. ${ }^{113-116}$ Whether these recommendations might apply to HCV-infected practitioners who want to be able to perform exposureprone invasive procedures (whether or not they have evidence of chronic hepatitis) is not addressed in this guideline.

\section{HIV}

Substantial progress also has been made for HIV. Tests to monitor HIV RNA viral load are now routine, and highly active antiretroviral therapy has been routinely given for more than a decade. None of the existing guidelines have incorporated treatment of the infected practitioner into the decision about practice restriction for HIV-infected providers who wish to continue performing exposure-prone invasive procedures.

\section{CURRENT PUBLISHED GUIDELINES}

In the United States, in the aftermath of the national and international publicity surrounding the instances of iatrogenic HIV infection linked to the Florida dentist, ${ }^{3-8}$ the CDC issued guidelines for HIV-infected and HBV-infected provid$\mathrm{ers}^{105}$ in July of 1991. From an implementation perspective, 3 aspects of these guidelines were problematic: (1) the need to classify a subset of invasive procedures as "exposureprone," (2) the requirement that an infected practitioner notify prospective patients of her or his infection status, and (3) the legal and administrative implementation strategies concerning the establishment and workings of the Expert Review Panel, an administrative requirement of the guidelines. Although we have witnessed substantial clinical progress and much has been written about these issues, these problems remain largely unresolved 18 years after publication of the original CDC guideline. ${ }^{105}$

The anxiety associated with the publicity surrounding the Florida dentist case-cluster prompted Congressional scrutiny of the 1991 CDC guideline, ${ }^{105}$ and, ultimately, resulted in the US Congress passing Federal legislation (PL. 102-141) requiring states to certify that they have implemented the July 1991 CDC guideline ${ }^{105}$ or "equivalent" guidelines. Interestingly, since the 1991 CDC guideline ${ }^{105}$ was published, the United States has identified no additional instances of provider-to-patient HIV transmission and only rare instances of 
either HCV or HBV transmission. The fact that only a small number of cases have been detected is attributable to a variety of factors, including less aggressive case-finding by the CDC and other local and state public health officials (ie, no active ongoing surveillance), the use of primary strategies to prevent exposure, and the efficacy of highly active antiretroviral therapy, which has lowered the viral burden in HIV-infected "source patients," has reduced the likelihood of hospitalization, and has decreased the need for and the numbers of invasive procedures that place healthcare workers at risk for exposure. To date, the management of infected practitioners therefore appears to have been effectively managed at the individual, the institutional or at the state level.

Although no new US Public Health Service guidelines regarding infected providers have been published since 1991, guidelines have been published outside the United States, and several articles have been published that argue differing points of view about this complex issue. The issue remains controversial for several complicated reasons. First, at least in part because of the manner in which HIV infection first presented in society, American public opinion has consistently reflected a "zero-risk" stance. Second, although most guidelines have focused on practice restrictions for infected providers who conduct exposure-prone procedures, a panel of experts convened by the CDC was unable to come to consensus about which invasive procedures are "exposure-prone," at least in part because of the substantial variability from provider to provider. The United Kingdom guidelines detail their definition of "exposure-prone" procedures. ${ }^{117}$ Also, recently, a group convened at the University of Virginia created a table of procedures, divided into 3 categories: (1) procedures with de minimis risk of viral transmission, (2) procedures for which viral transmission is theoretically possible but unlikely, and (3) procedures that are associated with a definite risk of viral transmission or that are directly characterized as exposure prone procedures. ${ }^{1}$ We have included a similar table in this guideline (Table 2), modified slightly from the table created by the University of Virginia group; the committee that drafted this guideline also expressed the strong opinion that some procedures listed under Category III might well be moved to Category II if the practitioner follows recommended work practice controls and uses appropriate safety devices. Third, this topic offers a unique confluence for the disciplines of epidemiology, medicine, ethics and law, and experts in these disciplines express widely divergent views about the optimal approach. Each of these issues deserves additional discussion.

Despite the fact that experts uniformly agree that infected providers who are not conducting invasive procedures present virtually no risk to their patients, as recently as 2005 , a study found that $89 \%$ of respondents acknowledged that they would want to know whether their doctor or dentist is infected with HIV; $82 \%$ agreed that disclosure of HBV or HCV infection in a provider should be mandatory; and only $38 \%$ thought that infected providers should be allowed to provide patient care of any kind. ${ }^{118}$ Some have argued that by not completely restricting providers infected with bloodborne pathogens, the discipline of medicine has betrayed its responsibility to patients. ${ }^{119}$ Because public opinion is far from aligned with the existing science base, a major issue becomes "What level of risk will society tolerate?"

\section{ETHICAL ISSUES}

A useful perspective is to consider the accommodations society has made for medical or psychiatric conditions in the healthcare worker, or a history of substance use, which also could put patients at risk. In certain cases, these conditions may necessitate restriction of the healthcare worker from certain aspects of healthcare practice. Restriction is not viewed as justified, however, when these conditions are well treated and the healthcare provider is able to practice in a safe and competent way.

Similarly, we feel that infection with a bloodborne pathogen does not itself justify restriction on the practice of an otherwise competent healthcare provider. As with providers who have medical, psychiatric, or substance-use problems, healthcare providers infected with bloodborne pathogens should seek ongoing care and treatment. SHEA recommends the additional protection of restricting health care providers from performing Category III procedures if the healthcare provider is infected with a bloodborne pathogen and meets other criteria, as delineated in this document.

The ethics of this issue are also complex. Healthcare providers have an ethical, professional and fiduciary responsibility to act in the best interests of their patients. Healthcare providers have a duty to ensure patient safety. The fact that healthcare providers are bound by the principle of nonmaleficence, which requires them to do no harm to patients and to do what is possible to prevent harm, is widely accepted. Nonetheless, this simple formulation of the principle of nonmaleficence provides limited guidance, because many beneficial interventions also present risks to patients. Consistent with the principle of nonmaleficence or "do not harm," healthcare providers are expected to act in accordance with the standards of their profession to prevent harm in the practice of patient care. Accordingly, healthcare providers have an obligation to follow the accepted standards of practice to prevent the transmission of bloodborne pathogens to patients. These standards include knowledge about and diligent utilization of infection control procedures, as well as careful attention to individual factors that can be controlled to reduce any risk of transmission.

Over the last 2 decades, considerable progress has been made in our understanding of HIV, HCV, and HBV infections. Sensitive tests to measure levels of circulating virus have been developed, as well as an impressive armamentarium of interventions to control the infections, including effective antiviral therapies for each disease. We know that when individuals are treated so that their viral load becomes and re- 
mains low or undetectable, the risk of transmission to others is greatly decreased. Technological and other advances in equipment and infection control procedures, as well as workpractice controls that have reduced the risk of occupational injuries to healthcare providers and, therefore, indirectly improved patient safety, have further reduced the risk of transmission in healthcare settings.

The accumulated experience and data provide reassuring evidence that the magnitude of risk for provider-to-patient transmission of HIV, HCV and HBV, although not zero, is exceedingly small. At the same time, the burdens of certain restrictions that have been placed on healthcare providers out of concern for patient safety have been disproportionately high. Qualified and experienced healthcare providers have suffered from discrimination, loss of privacy, liability, and loss of their jobs and their livelihoods. These burdens, associated with highly personal and stigmatizing diagnoses, seem unjustified in the face of an extremely low risk that can be further reduced by reasonable accommodations in the workplace and the diligence of healthcare providers and institutions.

All healthcare providers should comply with institutional policies and procedures designed to protect patients. Healthcare providers have an ethical responsibility to promote their own health and well being, and a responsibility to remove themselves from care situations if it is clear that there is a significant risk to patients despite appropriate preventive measures.

Infection with a bloodborne pathogen does not itself justify restriction on the practice of an otherwise competent healthcare provider. Healthcare providers infected with bloodborne pathogens should seek ongoing care and treatment. Restrictions may be justifiably imposed when a healthcare provider has a physical or mental impairment that affects his or her judgment and/or jeopardizes patient safety. Examples might include exudative lesions or weeping dermatitis; a history of poor infection-control technique or adherence to proper technique; mental confusion; or a prior incident of transmitting a bloodborne pathogen to a patient.

\section{LEGAL ISSUES}

From the legal perspective, the courts have been relatively unsupportive of infected healthcare providers. Although some authorities have argued that proscriptive state regulations are responding "to a problem that does not exist," 120 many legal actions were filed against infected healthcare providers and their institutions, based either on the CDC guidelines of July $1991,{ }^{10}$ professional societies' adoption of these guidelines, or both. In many, if not most of these actions, a practitioner was sued, not for infecting patients, but rather for inflicting mental anguish, for causing "pain and suffering," for assault, for the practitioner's failure to comply with the "duty to warn" the patient of risk, or for various other legal issues. Virtually all of these suits were filed because of the possibility that patients may have been unnecessarily exposed to the risk for infection, not because the patients were infected with bloodborne pathogens. Outcomes for these cases have been highly variable, and have not, to our knowledge, established a definitive precedent.

\section{HBV}

Existing US guidelines, published in 1991 and not, to date, ever revised, ${ }^{105}$ recommend that "healthcare providers who perform exposure-prone procedures and who do not have serologic evidence of immunity to HBV from vaccination or from previous infection should know their HBsAg status and, if that is positive, should also know their HBeAg status. If infected with HBV (and HBeAg positive) providers should not perform exposure-prone procedures unless they have sought counsel from an Expert Review Panel and been advised under what circumstances, if any, they may continue to perform these procedures. Such circumstances would include notifying prospective patients of the healthcare worker's seropositivity before they undergo exposure-prone invasive procedures." ${ }^{105}$

Several countries have issued modified guidelines for the management of HBV-infected providers based on the infected provider's circulating viral burdens. Unfortunately, the evidence base for these recommendations is minuscule, and the existing recommendations are quite disparate.

In the United Kingdom, HBV-infected providers who are $\mathrm{HBeAg}$ positive may not conduct exposure-prone invasive procedures; HBV-infected providers who are HBeAg negative but have HBV DNA levels of greater than $10^{3} \mathrm{GE} / \mathrm{mL}$ may not conduct exposure-prone invasive procedures; and HBVinfected providers who are $\mathrm{HBeAg}$ negative and have $\mathrm{HBV}$ DNA levels of less than $10^{3} \mathrm{GE} / \mathrm{mL}$ may conduct exposureprone invasive procedures but must be retested at least every 12 months to ensure that the level of viremia remains below $10^{3} \mathrm{GE} / \mathrm{mL} .{ }^{121}$ More recently, authorities in the United Kingdom have also recommended ${ }^{122}$ that HBV-infected healthcare providers who are $\mathrm{HBeAg}$ negative and who have pretreatment HBV DNA levels of $10^{3}-10^{5} \mathrm{GE} / \mathrm{mL}$ could be allowed to perform exposure prone procedures if they are receiving suppressive oral antiviral therapy and if their viral loads have decreased to below $10^{3} \mathrm{GE} / \mathrm{mL}$. The major challenge associated with this latter recommendation is the development of an effective monitoring strategy to make certain that the circulating viral burden remains less than $10^{3} \mathrm{GE} / \mathrm{mL} .^{122}$ The availability of various testing systems further complicates monitoring.

A European consortium was convened to create recommendations for HBV-infected providers and reached slightly different conclusions. ${ }^{123}$ In their recommendations, HBV-infected providers who are HBeAg positive are instructed that they may not perform exposure-prone procedures. ${ }^{123} \mathrm{HBV}-$ infected providers who are $\mathrm{HBeAg}$ negative but have $\mathrm{HBV}$ DNA levels of less than $10^{4} \mathrm{GE} / \mathrm{mL}$ may conduct exposure- 
prone invasive procedures but must be retested at least annually to make certain that the circulating viral burden remains below $10^{4} \mathrm{GE} / \mathrm{mL} .{ }^{123}$ These guidelines also emphasize that providers who are detected as having transmitted HBV should not perform exposure-prone procedures, and HBVinfected providers who have been treated and whose posttreatment DNA levels have fallen to less than $10^{4} \mathrm{GE} / \mathrm{mL}$ may conduct exposure-prone procedures but must be retested every 3 months to ensure that the viral burden remains below $10^{4} \mathrm{GE} / \mathrm{mL} .{ }^{123}$

Scientists from the Netherlands published a third set of recommendations suggesting that $\mathrm{HBV}$-infected providers who have HBV DNA levels of less than $10^{5} \mathrm{GE} / \mathrm{mL}$ may conduct exposure-prone invasive procedures, but must be retested at least annually. ${ }^{124}$

In a thoughtful analysis, van der Eijk et al ${ }^{125}$ listed the challenges to standardizing recommendations for practice restrictions for HBV-infected providers, emphasizing that guidelines have to strike a balance between excluding providers unnecessarily and patient safety. More recently, the Viral Hepatitis Prevention Board, a European consortium whose mission is to contribute to the control and prevention of viral hepatitis, convened a meeting of international experts from the public and private sectors to try to harmonize these recommendations. ${ }^{126}$ This meeting identified a number of issues that the contributors felt needed to be addressed before development of standardized recommendations, and consensus could not be achieved. ${ }^{126}$ Included in this list of issues are the following: (1) the variability of HBV DNA levels among chronically infected individuals; (2) the paucity of data linking levels of viremia to risk for transmission; (3) the variable reliability and reproducibility of the molecular tests used to measure HBV DNA, as well as the variability between the differing test systems; (4) the lack of standardization among the different tests used to detect HBV DNA; and (5) the variability and durability of therapeutic antiviral effects and, specifically, the length of time viremia can be effectively suppressed before "escape" mutant viruses emerge.

\section{$\mathrm{HCV}$}

No US Public Health Service guidelines address the management of providers infected with HCV, including the 1991 CDC recommendations. ${ }^{105}$ The UK guidelines ${ }^{109}$ are quite proscriptive regarding hepatitis $\mathrm{C}$, stating that $\mathrm{HCV}$-infected providers who have circulating HCV RNA may not conduct exposure-prone invasive procedures. Further, trainees found to have circulating HCV RNA should be restricted from starting training in exposure-prone invasive procedures. ${ }^{127}$ The UK guidelines also address treatment, noting that HCV-infected providers who have circulating HCV RNA who receive antiviral treatment and become HCV RNA negative for a period of 6 months can be permitted to return to performing exposure-prone invasive procedures but must be retested in 6 months to confirm the durability of the response. ${ }^{109}$
The European Consortium could not reach consensus about the management of $\mathrm{HCV}$-infected providers, concluding that "on balance it is not recommended that exposureprone procedures be forbidden for HCV-infected healthcare workers." ${ }^{223}$ Similarly, the scientists from the Netherlands addressed only HBV infection, and did not discuss HCV-infected providers. ${ }^{124}$ Furthermore, the findings of the Viral Hepatitis Prevention Board with respect to HBV (eg, variable HBV DNA levels, paucity of data linking levels of viremia to risk for transmission, variable rates of reliability and reproducibility of molecular tests used to measure HBV DNA, variability and lack of standardization of the differing test systems, variability and durability of therapeutic antiviral effects, and length of time viremia can be effectively suppressed before "escape" mutant viruses emerge) also apply to individuals chronically infected with HCV.

\section{HIV}

The UK guidelines ${ }^{117}$ recommend restriction of the practice of HIV-infected providers. ${ }^{105}$ The US guidelines recommend that HIV-infected practitioners, "not perform exposure-prone procedures unless they have sought counsel from an Expert Review Panel and been advised under what circumstances, if any, they may continue to perform these procedures. Such circumstances would include notifying prospective patients of the HCW's seropositivity before they undergo exposureprone invasive procedures." ${ }^{\prime 105}$ Neither guideline bases recommendations on the clinical status of the infected provider or on the viral burden of the HIV-infected provider.

\section{CURRENT ASSESSMENT}

SHEA emphasizes that, more than 20 years after the publication of the "Universal Precautions" guidelines, ${ }^{128}$ blood and potentially contaminated body fluids (eg, cerebrospinal fluid, peritoneal fluid, amniotic fluid, pleural fluid, synovial fluid, pericardial fluid, semen, vaginal secretion, and any bloodcontaminated fluid) from any patient must be considered to have the potential to transmit bloodborne pathogens, irrespective of the patient's primary or secondary diagnosis. Although this principle was initially intended to apply to patients, we find it equally relevant to healthcare providers who may be infected with HIV, HBV, HCV, and/or another bloodborne pathogen. The magnitude of risk for provider-to-patient transmission of bloodborne pathogens may never be known with precision; however, the additional experience gained over the past 20 years provides reassuring evidence that these risks are extremely small.

In the previous version of this guideline, SHEA expressed the opinion that most of the issues applicable to HBV-infected providers would generally apply to providers who are infected with HIV and might also hold for providers infected with HCV. In this revised version, SHEA decided to deal with each of the pathogens individually—at least with respect to setting policies for infected providers. This decision was made for a 


\begin{tabular}{|c|c|}
\hline Category and grade & Definition \\
\hline \multicolumn{2}{|c|}{ Strength of recommendation } \\
\hline A & Good evidence to support a recommendation for use \\
\hline $\mathrm{B}$ & Moderate evidence to support a recommendation for use \\
\hline $\mathrm{C}$ & Poor evidence to support a recommendation for or against use \\
\hline $\mathrm{D}$ & Moderate evidence to support a recommendation against use \\
\hline $\mathrm{E}$ & Good evidence to support a recommendation against use \\
\hline \multicolumn{2}{|l|}{ Quality of evidence } \\
\hline I & Evidence exists from at least one properly randomized, controlled trial \\
\hline II & $\begin{array}{l}\text { Evidence comes from at least one well-designed clinical trial without } \\
\text { randomization, from cohort or case-controlled analytic studies } \\
\text { (preferably from more than one center), from multiple time-series } \\
\text { studies, or from dramatic results in uncontrolled experiments }\end{array}$ \\
\hline III & $\begin{array}{l}\text { Evidence comes from opinions of respected authorities, based on clin- } \\
\text { ical experience, descriptive studies, or reports of expert committees }\end{array}$ \\
\hline
\end{tabular}

NOTE. The classification scheme is that developed by the Infectious Diseases Society of America, ${ }^{134}$ which are adapted from the Canadian Task Force on the Periodic Health Examination. ${ }^{135}$

variety of reasons. First, the "average" risk for transmission following a single parenteral exposure is at least 10-fold and probably 100-fold higher for HBV than for HIV. The risk for $\mathrm{HCV}$ transmission appears to be intermediate between those for HIV and HBV. ${ }^{65}$ Second, chronic carriers of these 3 viral pathogens typically exhibit substantial differences in viral burden (ie, the number of intact virions per milliliter of blood); thus, circumstances that might involve a measurable risk for transmission of $\mathrm{HBV}$ may not necessarily be associated with a measurable risk for transmission of HIV. Third, postexposure management strategies, including treatment, have evolved considerably, and treatment for each of these diseases since the previous version of this guideline was published. Pre-exposure receipt of hepatitis $B$ vaccine has led to a dramatic decrease in the incidence of HBV infection in healthcare personnel. Further, postexposure prophylaxis for HBV infection using hepatitis B immune globulin and/or hepatitis B vaccine is both safe and highly effective. Although its efficacy has not been proven in a clinical trial, postexposure prophylaxis for HIV infection using 2-drug or 3-drug combinations has likely contributed to the dramatic decrease in occupationally acquired HIV infection in healthcare workers in the United States. The last such case documented by the CDC occurred in $1999 .^{70,129}$ Unfortunately, neither pre-exposure nor postexposure prophylaxis exist for HCV.

For these reasons, the version of this guideline will continue to consider each pathogen individually. The following recommendations are based on the following information: (1) available scientific information about the magnitude of risk for provider-to-patient transmission of the bloodborne pathogens; (2) clinical hospital epidemiology and infection control experience and management of $\mathrm{HBV}, \mathrm{HCV}$ and HIV related problems in the healthcare setting since 1981; and (3) experience with the implementation and interpretation of prior recommendations and guidelines, including those issued pre- viously by the US Public Health Service. ${ }^{102,130-133}$ The recommendations are classified according to the scheme developed by the Infectious Diseases Society of America ${ }^{134}$ (Table 4).

\section{GUIDELINE RECOMMENDATIONS}

\section{BACKGROUND AND RATIONALE}

These recommendations are based on the thorough consideration of the risks for provider-to-patient transmission of these pathogens, from the information provided by (1) the past 50 years' experience with these pathogens in the healthcare setting; (2) the reported experience with HBV-infected providers and their patients ${ }^{11-16,61-63,136}$ (I. Williams, CDC, Personal Communication), $\mathrm{HCV}$-infected providers and their patients, ${ }^{18-32,35,37,39,40,64}$ and HIV-infected providers and their patients ${ }^{3-8,41-57}$; (3) studies of the frequency of various types of occupational exposures ${ }^{65,71-79,137,138}$; (4) studies of the magnitude of risk of transmission of bloodborne pathogens following various types of exposures ${ }^{70,104,139,140}$; (5) the substantial progress biomedical science has made in accurately measuring viral burden as an indicator of disease activity, and, possibly, infectivity, for all 3 viral infections; (6) the availability of an effective vaccine for HBV; (7) the development of effective postexposure management strategies, as well as therapy that can substantially suppress HIV and HBV infection and can suppress and even cure HCV infection; (8) progress made in modifying procedures and devices to create a safer healthcare environment; and (9) the resources required to develop a unique administrative approach for the management of providers infected with these 3 bloodborne pathogens.

The major changes in the risk calculus since the publication of our prior set of recommendations are, first, that effective antiviral therapeutic interventions have been developed for 
all 3 pathogens, and, second, that a number of engineering and work-practice controls have been introduced into the healthcare environment that have contributed substantially to decreasing the risk for occupational injuries to healthcare providers and, therefore, indirectly, to improving patient safety.

\section{PRACTICE ISSUES}

1. Should healthcare providers who are infected with HBV be allowed to practice? If so, under what clinical, serological, or viral burden parameters?

\section{Recommendation}

All blood and potentially blood-containing fluids (ie, cerebrospinal fluid, peritoneal fluid, amniotic fluid, pleural fluid, synovial fluid, pericardial fluid, semen, vaginal secretion, and any bloodcontaminated fluid) from patients and providers must be regarded as potentially infectious for HBV (A-III). All providers should follow the tenets of Standard Precautions (A-III). Only the following body fluids have been implicated in the transmission of bloodborne viruses: blood, blood products, semen, cervical secretions, cerebrospinal fluid, peritoneal fluid, pleural fluid, synovial fluid, pericardial fluid, and amniotic fluid. Transfers of blood or other potentially infectious materials from providers to patients must be avoided (A-III). Tears, saliva, vomitus, sputum, urine and stool are not considered to be capable of transmitting bloodborne viruses unless contaminated with blood. Nonetheless, healthcare providers should practice Standard Precautions and avoid contact with these fluids, as they are potentially infectious for additional pathogens (eg, saliva for herpes simplex virus, stool for hepatitis A virus).

HBV-infected healthcare providers should not be prohibited from participating in patient-care activities solely on the basis of their HBV infection (A-III). HBV-infected providers should not be restricted from participating in Category I or Category II Procedures (Table 2) (A-III). Providers infected with HBV who are either $\mathrm{HBeAg}$ positive or who have circulating viral burdens greater than or equal to $10^{4} \mathrm{GE} / \mathrm{mL}$ should refrain from performing Category III procedures (A-III). Healthcare providers who have circulating HBV burdens of less than $10^{4} \mathrm{GE} / \mathrm{mL}$ should be allowed to perform those Category III activities identified as associated with a risk for provider-to-patient transmission of bloodborne pathogens, so long as the infected provider (1) is not detected as having transmitted infection to patients; (2) obtains advice from an Expert Review Panel about continued practice; (3) undergoes follow-up routinely by Occupational Medicine staff (or an appropriate public health official), who tests the provider twice per year to demonstrate the maintenance of a viral burden of less than $10^{4} \mathrm{GE} / \mathrm{mL}$; (4) also receives follow-up by a personal physician who has expertise in the management of HBV infection and who is allowed by the provider to communicate with the Expert Review Panel about the provider's clinical status; (5) consults with an expert about optimal infection control procedures (and strictly adheres to the recommended procedures, including the routine use of double-gloving for Category II and Category III procedures and frequent glove changes during procedures, particularly if performing technical tasks known to compromise glove integrity [eg, placing sternal wires]); and (6) agrees to the information in and signs a contract or letter from the Expert Review Panel that characterizes her or his responsibilities (discussed in more detail in Recommendation 8, below) (A-III).

Discussion. We have chosen a cut-off of $10^{4} \mathrm{GE} / \mathrm{mL}$ to separate providers who can and cannot perform Category III procedures. This level was chosen in the absence of data that definitively associate a given level with either a clear risk for transmission or, more importantly, an absence of risk. As noted above, one modeling experiment suggested that the most common types of exposure to a provider who had a viral burden of $10^{4} \mathrm{GE} / \mathrm{mL}$ would be associated with an exposure to less than 1 virion. ${ }^{100}$ In addition to that modeling experiment, another important piece of evidence that supports this threshold is the fact that, in all of the instances of transmission from an HBeAg-negative provider to a patient in which the source provider's viral burden has been measured, the implicated provider had a circulating viral burden in excess of $10^{4} \mathrm{GE} / \mathrm{mL},{ }^{123}$ except in one case, ${ }^{141}$ and the validity of that one case has been questioned, because the sample was taken from the provider more than 3 months after the transmission occurred. ${ }^{124}$ Setting the cutoff for the circulating HBV viral burden at $10^{3} \mathrm{GE} / \mathrm{mL}$ would have resulted in restricting the practices of $58 \%$ of the HBV-infected providers in the United Kingdom and nearly $95 \%$ of such providers in the Netherlands. ${ }^{126}$

These guidelines suggest a cutoff of $10^{4} \mathrm{GE} / \mathrm{mL}$ and allow an individual who has a circulating viral load of less than $10^{4}$ $\mathrm{GE} / \mathrm{mL}$ to continue to conduct Category III procedures as long as the individual (1) is not detected as having transmitted infection to patients; (2) obtains advice from an Expert Review Panel about continued practice; (3) undergoes followup routinely by Occupational Medicine staff (or an appropriate public health official), who tests the provider twice per year to demonstrate the maintenance of a viral burden of less than $10^{4} \mathrm{GE} / \mathrm{mL}$; (4) also receives follow-up by a personal physician who has expertise in the management of HBV infection and who is allowed by the provider to communicate with the Expert Review Panel about the provider's clinical status; (5) consults with an infection control expert about optimal infection control procedures (and strictly adheres to the recommended procedures, including the routine use of double-gloving for Category II and Category III procedures, use of puncture-resistant gloves, use of blunted surgical needles ${ }^{86,97-99}$ use of "hands-free" technique, ${ }^{142}$ and other work practice controls, among many others); and (6) agrees to the information in and signs a contract or letter from the Expert Review Panel that characterizes her or his responsibilities (discussed in more detail in Recommendation 8, below). If a provider is receiving treatment for this infection, the efficacy of the treatment should be considered in the 
context of the specific infection being treated. In general, because of their very high viral burdens, providers who have acute $\mathrm{HBV}$ infection and those who have HBV infection in the absence of immunological responses should not perform Category III procedures. Providers whose infections have resolved and who have no evidence of circulating virus should not be restricted in any way.

Individuals relying on these guidelines must keep in mind that each such case must be evaluated on its own merit and that the molecular testing strategies discussed in the document are subject to several limitations. These include (1) the fact that infected individuals' HBV DNA levels may vary over time, (2) there are limited scientific data linking levels of viremia to risk for transmission, (3) the fact that the different currently marketed test for measuring HBV viral burden may produce variable results (4) the varying level of reproducibility of these molecular tests, (5) the fact that antiviral therapy may produce transient or limited responses (particularly with respect to monotherapy for HBV), and (6) the variety of virological and patient-related factors (eg, adherence to the recommended antiviral regimen) that may contribute to the development of "escape" mutants. SHEA underscores that these guidelines are, of necessity, malleable and modifiable as more information becomes available.

Antiviral therapy clearly reduces the circulating HBV viral burden to levels below acceptable cutoff values. ${ }^{143}$ Since, to date, therapies have been suppressive and not curative, this approach is associated with the clear possibility of antiviral agent-related toxicity, as well as the theoretical possibility of fostering resistance among viruses from the infected provider. The effect of therapy should be considered carefully by the Occupational Medicine physician and the Expert Review Panel, as well as by the provider's personal physician who has expertise in the management of HBV infection.

\section{Should healthcare providers who are infected with $\mathrm{HCV}$ be allowed to practice? If so, under what clinical, serological or viral burden parameters?}

\section{Recommendation}

HCV-infected providers should not be prohibited from participating in patient-care activities solely on the basis of their HCV infection (A-III).

$\mathrm{HCV}$-infected providers should not be restricted from participating in Category I or Category II Procedures (A-III); providers infected with HCV who have circulating viral burdens of greater than or equal to $10^{4} \mathrm{GE} / \mathrm{mL}$ should refrain from performing Category III procedures (B-III).

Healthcare providers who have circulating HCV burdens of less than $10^{4} \mathrm{GE} / \mathrm{mL}$ should be allowed to perform those Category III activities identified as associated with a risk for provider-topatient transmission of bloodborne pathogens, so long as the infected provider (1) is not detected as having transmitted infection to patients; (2) obtains advice from an Expert Review Panel about continued practice; (3) undergoes follow-up rou- tinely by Occupational Medicine staff (or an appropriate public health official), who tests the provider twice per year to demonstrate the maintenance of a viral burden of less than $10^{4} \mathrm{GE} /$ $\mathrm{mL}$; (4) also receives follow-up by a personal physician who has expertise in the management of HCV infection and who is allowed by the provider to communicate with the Expert Review Panel about the provider's clinical status; (5) consults with an expert about optimal infection control procedures (and strictly adheres to the recommended procedures, including the routine use of double-gloving for Category II and Category III procedures and frequent glove changes during procedures, particularly if performing technical tasks known to compromise glove integrity [eg, placing sternal wires]); and (6) agrees to the information in and signs a contract or letter from the Expert Review Panel that characterizes her or his responsibilities (discussed in more detail in Recommendation 8, below) (B-III).

Discussion. These guidelines recommend that HCV-infected healthcare providers who have circulating viral burdens of less than $10^{4} \mathrm{GE} / \mathrm{mL}$ not be restricted from any aspect of health care so long as the infected provider follows the detail of the recommendation. Specifically, the provider must be willing to consult with, and follow the recommendations of, an infection control expert. The infected provider must strictly adhere to the recommended procedures (eg, routine use of double-gloving for Category II and III procedures, frequent glove changes during procedures, particularly if performing technical tasks known to compromise glove integrity [eg, placing sternal wires], use of puncture-resistant gloves, blunted surgical needles, ${ }^{86,97-99}$ "hands-free" technique ${ }^{142,144}$ and other work practice controls, among many others). Finally, the infected provider must agree to the information in, and sign, a contract or letter from the Expert Review Panel that characterizes her or his responsibilities. One might have easily argued for no restrictions whatsoever for HCV-infected providers, on the basis of the experience in the United States alone.

The selection of a practice-restriction-threshold of $10^{4} \mathrm{GE} /$ $\mathrm{mL}$ is arbitrary, but, as noted above (in the section Legal Issues), some European guidelines have taken a far more restrictive tack. Because there have been virtually no such cases in the United States, we have, nonetheless, chosen a conservative cutoff for restricting practitioners. We have recommended practice restrictions for providers who perform Category III procedures whose viral burdens are $10^{4} \mathrm{GE} / \mathrm{mL}$ or greater. We have based this decision on the in vitro HBV data cited above (in the section Pathogenesis and Transmission Risk), as well as the clinical experience with patient-toprovider transmission of $\mathrm{HCV}$ in the United Kingdom. In addition, we note that therapy for HCV is becoming increasingly effective, so that many providers who are identified as infected with HCV can have their infections eradicated. Studies of the efficacy of the treatment of acute HCV infection often demonstrate cure rates in excess of $95 \%$, with studies of the treatment of chronically infected individuals demon- 
strating cure rates of up to $70 \%$ or $80 \%$, particularly for individuals infected with a treatment-favorable genotype. ${ }^{145-147}$

Individuals relying on these guidelines must keep in mind that each such case must be evaluated on its own merit and that the molecular testing strategies discussed in the document are subject to several limitations. These include (1) the fact that infected individuals' HCV RNA levels may vary over time, (2) the paucity of scientific data linking levels of viremia to risk for transmission, (3) the fact that the different currently marketed test for measuring $\mathrm{HCV}$ viral burden may produce variable results, (4) the varying level of reproducibility of these molecular tests, (5) the fact that antiviral therapy may produce transient or limited responses, and (6) the variety of virological and patient-related factors (eg, adherence to the recommended antiviral regimen) that may contribute to the development of "escape" mutants. SHEA underscores that these guidelines are, of necessity, malleable and modifiable as more information becomes available.

3. Should healthcare providers who are infected with HIV be allowed to practice? If so, under what clinical, serological or viral burden parameters?

\section{Recommendation}

HIV-infected healthcare providers should not be prohibited from participating in patient-care activities solely on the basis of their HIV infection (A-III). HIV-infected providers should not be restricted from participating in Category I or Category II procedures; providers infected with HIV who have circulating viral burdens equal to or in excess of $5 \times 10^{2} \mathrm{GE} / \mathrm{mL}$ should refrain from performing Category III procedures (A-III). Healthcare providers who have circulating HIV burdens of less than $5 \times 10^{2}$ $\mathrm{GE} / \mathrm{mL}$ should be allowed to perform those Category III activities identified as associated with a risk for provider-to-patient transmission of bloodborne pathogens, so long as the infected provider (1) is not detected as having transmitted infection to patients; (2) obtains advice from an Expert Review Panel about continued practice; (3) undergoes follow-up routinely by Occupational Medicine staff, who test the provider twice per year to demonstrate the maintenance of a viral burden of less than $5 \times 10^{2} \mathrm{GE} /$ $\mathrm{mL}$; (4) also receives follow-up by a personal physician who has expertise in the management of HIV infection and who is allowed by the provider to communicate with the Expert Review Panel about the provider's clinical status; (5) consults with an expert about optimal infection control procedures (and strictly adheres to the recommended procedures, including the routine use of double-gloving for Category II and Category III procedures and frequent glove changes during procedures, particularly if performing technical tasks known to compromise glove integrity [eg, placing sternal wires]); and (6) agrees to the information in and signs a contract or letter from the Expert Review Panel that characterizes her or his responsibilities (discussed in more detail in Recommendation 8, below) (B-III).

Discussion. These guidelines recommend that HIV-infected healthcare providers who have circulating viral burdens of less than $5 \times 10^{2} \mathrm{GE} / \mathrm{mL}$ not be restricted from any aspect of health care, so long as the infected provider follows the detail of the recommendation. Specifically, the provider must be willing to consult with, and follow the recommendations of, an infection control expert. The infected provider must strictly adhere to the recommended procedures, (eg, routine use of double-gloving for Category II and III procedures; frequent glove changes during procedures, particularly if performing technical tasks known to compromise glove integrity [eg, placing sternal wires]; use of puncture-resistant gloves blunted surgical needles, ${ }^{86,97-99}$ and "hands-free" technique, ${ }^{142,144}$ and other work practice controls, among many others). Finally, the infected provider must agree to the information in, and sign, a contract or letter from the Expert Review Panel that characterizes her or his responsibilities.

As is the case for our recommendations for HBV-infected practitioners and HCV-infected practitioners, we acknowledge that the selection of a practice-restriction-threshold of $5 \times 10^{2} \mathrm{GE} / \mathrm{mL}$ is arbitrary; however, as noted above (in the section on Legal Issues), European guidelines have taken a far more restrictive tack. Because no provider-to-patient transmissions of HIV infection have been detected in the United States since the initial cases involving the Florida dentist (discussed in more detail in the sections Epidemiology and Current Published Guidelines, above), we have chosen to recommend permitting an HIV-infected practitioner to conduct Category III procedures if his or her viral burden is suppressed below $5 \times 10^{2} \mathrm{GE} / \mathrm{mL}$. We chose $5 \times 10^{2} \mathrm{GE} / \mathrm{mL}$ as the threshold, in part, because individuals who typically have their viral burdens suppressed to the "undetectable" range (generally $<50$ copies $/ \mathrm{mL}$ ) occasionally have levels that spike to $5 \times 10^{2} \mathrm{GE} / \mathrm{mL}$, despite ongoing effective antiretroviral therapy. We have recommended practice restrictions for a provider who performs Category III procedures and has a viral burden of $5 \times 10^{2} \mathrm{GE} / \mathrm{mL}$ or greater. Because this recommendation represents a substantial departure from other similar guidelines, we have recommended a relatively low threshold for restriction. Since data do not exist to provide evidence for the most appropriate threshold, this lower threshold was selected solely on the basis of opinions of the committee that drafted this guideline. This threshold should be revisited on a regular basis and modified on the basis of additional accumulating experience. Our committee also noted that highly active antiretroviral therapy is continuing to improve to the point that most HIV-infected providers can have their infections suppressed to this level or below. SHEA underscores that these guidelines are, of necessity, malleable and can be modified as more information becomes available.

Individuals relying on these guidelines must keep in mind that each such case must be evaluated on its own merit and that the molecular testing strategies discussed in the document are subject to several limitations. These include (1) the fact that infected individuals' circulating HIV levels may vary over time, (2) the paucity of scientific data linking levels of 
viremia to risk for transmission, (3) the fact that the different currently marketed test for measuring viral burden may produce variable results, (4) the current variability in the level of reproducibility of these molecular tests, (5) the fact that antiviral therapy may produce transient or limited responses, and (6) the variety of virological and patient-related factors (eg, adherence to the recommended antiviral regimen) that may contribute to the development of "escape" mutants. In general, because of their very high viral burdens, providers who are experiencing the HIV seroconversion illness should not perform Category III procedures.

4. For providers who are infected with $\mathrm{HBV}, \mathrm{HCV}$, and/or HIV and who have circulating viral burdens greater than the recommended cutoff values, which procedures should they be precluded from performing?

\section{Recommendation}

HBV, HCV, and HIV infected providers should not be restricted from participating in Category I or Category II Procedures solely on the basis of their bloodborne pathogen infection (A-III). HBVinfected providers who are either $\mathrm{HBeAg}$ positive or who have circulating HBV burdens greater than or equal to $10^{4} \mathrm{GE} / \mathrm{mL}$ should refrain from conducting procedures listed in Category III (A-III). HCV-infected providers who have circulating viral burdens greater than or equal to $10^{4} \mathrm{GE} / \mathrm{mL}$ should refrain from conducting procedures listed in Category III (B-III). HIV-infected providers who have circulating viral burdens greater than or equal to $5 \times 10^{2} \mathrm{GE} / \mathrm{mL}$ should refrain from conducting procedures listed in Category III (A-III).

Discussion. Historically, the concept of "exposure-prone" procedures has been a point of controversy, though several more recent guidelines and manuscripts have suggested that "exposure-prone" procedures can be defined. ${ }^{1,109,117,121}$ In the previous version of this guideline, SHEA suggested that "exposure-prone" procedures might be defined as those that have been "epidemiologically implicated" in patient-to-provider transmission. This approach has proved to be flawed; for example, one recent case-cluster of provider-to-patient transmission of HBV suggested that the implantation of electroencephalography electrodes was implicated in the transmission of HBV. ${ }^{16}$ No guideline would include implantation of electroencephalography electrodes as an "exposure-prone" procedure. Some authorities have suggested that providers, rather than procedures, might be exposure-prone, suggesting that technical expertise and experience may play a more substantive role in the risk for provider-to-patient exposure, rather than the procedures themselves. We favor a modification of the approach taken by Reitsma et $\mathrm{al}^{1}$; namely, 3 tiers of procedural risk (Table 2). Most guidelines do not consider the impact of the introduction of safer devices and safer work practice controls to the risk calculus for infections with these 3 pathogens. As noted above in the section Path- ogenesis and Transmission Risk, the use of reinforced gloves, ${ }^{91,92}$ double gloves, glove-liners, or other devices or materials to protect the provider's hands, ${ }^{89,91,93-96}$ and use of blunted suture needles, ${ }^{86,97-99}$ as well as a variety of other safer devices and work practices, have been shown to decrease the risks for percutaneous injuries. The members of the committee drafting this guideline emphasized that the consistent use of safety devices by a practitioner should be one factor considered by the Expert Review Panel when deciding about practice restrictions. Some members of the committee felt that consistent use of these procedures and techniques might move some procedures from Category III to Category II for individual practitioners.

\section{If restricted from performing certain types of} procedures, should providers who are infected with $\mathrm{HBV}$, $\mathrm{HCV}$, and/or HIV be restricted on the basis of (A) clinical status, (B) laboratory parameters of disease activity and/or progression (and, if so, at what specific "set-points" for each infection), and/or (C) clinical performance (eg, technical skill or lack of adherence to important infection control procedures); and if so, who measures and who decides, and what are the criteria for restriction?

\section{Recommendation}

Healthcare practice restrictions should be based on several factors, including (1) evidence of transmission of infection to patients; (2) advice from the Expert Review Panel about continued practice, (3) advice from the Occupational Medicine specialist who is following up the provider, (4) advice from the provider's physician who has expertise in the bloodborne pathogen infection, (5) viral burden measurements of greater than or equal to $10^{4} \mathrm{GE} / \mathrm{mL}$ (for $\mathrm{HBV}$ or $\mathrm{HCV}$ infection) or greater than or equal to $5 \times 10^{2} \mathrm{GE} /$ $\mathrm{mL}$ (for HIV infection), (6) lack of adherence to recommended infection control procedures, and (7) inability to safely provide patient care (eg, development of another contagious disease such as tuberculosis or development of a bloodborne pathogen-associated disorder, such as HIV-associated neurological disease) (A-III).

Discussion. SHEA recommends that restrictions should be based on various combinations of these data. Anyone clearly implicated in the transmission of one of these organisms should become the subject of scrutiny. The factors listed above (ie, clinical status, laboratory parameters, and clinical performance) all contribute to the assessment of the individual's ability to practice safely. This ongoing assessment is one of the important roles that should be assumed by the Expert Review Panel (discussed in detail in Recommendation 8 , below). The expert review panel and the occupational medicine physician should also consider the possibility of narcotics diversion in the transmission of these infections. Providers identified as acutely infected with any of these pathogens should be carefully evaluated for viral burdens and 
should engage the expert review panel through their occupational medicine and/or public health practitioners.

\section{Should students, residents, fellows, and other trainees who are infected with HBV, HCV, and/or HIV be discouraged from entering certain specialties and/or subspecialities? How and by whom should these decisions be made?}

\section{Recommendation \\ Healthcare institutions should make certain that students and trainees are fully educated about the risks associated with testing of themselves for, and management of patients with, bloodborne pathogen infections (A-III). All providers who are at risk for occupational exposure to blood should be immunized with the hepatitis B vaccine, unless it is contraindicated (A-I). All health- care providers should know their serological status with respect to antibody to HBsAg, which should be measured 1-6 months after the completion of their HBV immunization series (A-III). Institutions should assist students and trainees who are deter- mined to be infected with bloodborne pathogens in identifying and selecting career choices that will be the least influenced by their infection(s) (A-III). Healthcare institutions should maintain the privacy and medical confidentiality of students and trainees identified as infected with bloodborne pathogens (A-III). HBV- infected students and trainees who are either $\mathrm{HBeAg}$ positive or who have circulating HBV burdens greater than or equal to $10^{4}$ $\mathrm{GE} / \mathrm{mL}$ should refrain from training in or conducting procedures listed in Category III (A-III); HCV-infected students and trainees who have circulating viral burdens in excess of $10^{4} \mathrm{GE} / \mathrm{mL}$ should refrain from training in or conducting procedures listed in Cat- egory III (B-III); HIV-infected students and trainees who have circulating viral burdens greater than or equal to $5 \times 10^{2} \mathrm{GE} / \mathrm{mL}$ should refrain from conducting procedures listed in Category III (B-III). Students and trainees who are not receiving optimal ther- apy for their bloodborne pathogen infection(s) should seek such treatment $(\mathrm{A}-\mathrm{I})$.}

Discussion. A special problem arises when a training institution becomes aware that a trainee is chronically infected with a bloodborne pathogen. Each of these instances should be handled on a case-by-case basis, in consultation with the institution's legal counsel, the house staff training director, infection control professionals, the Dean of the school, and others who are involved stakeholders. To date, these cases have been handled unevenly across the United States, with some institutions focusing on the disability-law aspects and others focusing on liability. ${ }^{90}$ The law concerning these issues is changing rapidly and is relatively untested in the higher courts. The institution, however, does have responsibility to make certain that the trainee is fully informed about the risks - both to the trainee and to his or her patients-associated with clinical practice. The institution should under- score the importance of appropriate treatment and the importance of adherance to infection control recommendations. The institution should assist the trainee in selecting a career path best suited to her or his specific situation and should provide reasonable accommodation to students and trainees who have disabling conditions. By adopting the modification of the position initially proffered by Reitsma et $\mathrm{al}^{1}$ (ie, the 3tiered risk schema), SHEA advocates encouraging trainees who are infected with HBV, HCV, and/or HIV and whose infection(s) cannot be effectively cleared or whose infections cannot be suppressed below the thresholds identified in Recommendations 1, 2, and 3 (above), to select career paths that do not involve the highest-risk procedures. In instances in which the decision is made to continue training, SHEA advocates having the student be closely supervised by an attending provider who is aware of the student's status when the student is learning or performing Category II procedures.

\section{Should providers infected with HBV, HCV, and/or HIV be subject to specific monitoring programs, and, if so, how and by whom and to whom should the data be reported?}

\section{Recommendation \\ Providers infected with HBV, HCV, and/or HIV who perform Category III procedures should have their circulating viral bur- dens measured at least every 6 months by an engaged occupational medicine practitioner and should undergo periodic evaluations (at a minimum, twice per year) by a physician selected by the provider who has demonstrated expertise in the management of the provider's infection. Results of the viral burden tests should be reviewed by the Occupational Medicine physician, should be reviewed with the provider's personal physician, and should be evaluated by the provider's Expert Review Panel (A-III).}

Discussion. Because the guidelines recommend viral burden cutoffs for practice restrictions, SHEA believes that an ongoing monitoring program is essential. Most molecular assay results are reproducible only within about half an order of magnitude. A fraction of infected individuals have fluctuating viral burdens. SHEA recommends a major role for the Occupational Medicine practitioner in supervising the monitoring program. This role would include, but not be limited to, measuring the provider's circulating viral burden at least twice annually and providing advice to the Expert Review Panel about the provider's progress and ongoing clinical status. For independent practitioners working only from an office, these functions should be fulfilled by the city, county or state health department (consonant with state and local laws). Elements of follow-up are summarized in Table 5. 
TABLE 5. Functions of the Expert Review Panel

1. Evaluation of the infected provider's clinical status

2. Assessment of the provider's viral burden data

3. Assessment of the provider's experience and expertise

4. Assessment of the procedures performed by the provider and the specific techniques used to perform these procedures

5. Determination of the extent to which the provider adheres to accepted infection control precautions

6. Provision of recommendations about the use of specific barriers, work practice controls, and infection prevention strategies for the conduct of specific procedures and assess the provider's willingness to adhere to these recommendations

7. Provision of counseling to the provider about her or his ethical obligation to report a patient exposure, should one occur, and about the appropriate procedures to follow, should an exposure occur

8. Develop and execute a contract between the infected provider and the Expert Review Panel and/or institution (see Table 5)

9. In instances in which transmission is suspected, consider the potential for narcotics diversion

10. Notify Risk Management should a breach in procedure or a patient exposure occur

11. Notification of the appropriate licensure board for breaches of the signed contract with the Expert Review Panel (if required by state regulations)

NOTE. In instances in which an infected provider is not institutionally based, this responsibility should fall to the local or state health department (consonant with existing state laws).

8. Prior recommendations have suggested the creation of an Expert Review Panel for assisting institutions in managing providers infected with bloodborne pathogens. Is there a role for such a panel in 2009 and beyond? If so, what is that role, and at what level should the committee be convened (eg, at the institutional, city, or state level), who should comprise such a committee, what should be the committee's charge, and how and by whom should the committee be managed? Do committee members accept liability for participation?

\section{Recommendation}

Healthcare providers infected with HBV, HCV, and/or HIV should have their clinical status and laboratory data reviewed by an Expert Review Panel (A-III). Such a panel could exist at a state, regional, county, city, or institutional level, consonant with the individual provider's circumstance and with state and local laws. The review panel should include, but not necessarily be limited to, individuals who have expertise in the infected provider's specialty or subspecialty, Healthcare Epidemiology, Infectious Diseases or Hepatology (specifically with expertise in the bloodborne pathogen[s] being discussed), Occupational Medicine, and/or hospital administration; the infected provider's physician; a public health official (in states in which this issue is managed at the state level); a human resources professional; and, perhaps, an individual with legal and/or ethics expertise. The review panel will advise the healthcare provider, the Occupational Medicine physician, and/or the patient's primary physician about the provider's practice and about the advisability of her or his performing Category III procedures, as well as about the use of infection control interventions (A-III). The panel will create a contract or letter detailing the provider's responsibilities and those of the panel (Figure 1). Before the provider returns to practice, this document must be agreed to and signed by the provider and the panel chair (A-III). The panel should reconsider the provider's performance in the event any of the following occurs: the provider's viral load increases to above the recommended level for consideration of restrictions from performing Category III procedures; the provider develops another contagious disease (eg, tuberculosis); the provider develops another condition that might adversely effect patient safety (eg, HIV-associated neurological impairment or hepatic encephalopathy); the provider fails to strictly adhere to recommended infection control practices; a patient is exposed to a potentially contaminated body fluid of the provider; and/or if there is evidence of provider-to-patient transmission (A-III). The entity chartering the panel should indemnify the panel members against any legal risks and/or costs (A-III).

Discussion. SHEA believes that the creation of an Expert Review Panel to assist in the management of these providers is an important aspect of a patient safety program. Such a program could exist at a state, county, city or institutional level. We believe that the fact that no such cases have received publicity in the United States since the early part of this decade is an indirect reflection of the efficacy of this approach. The basic functions of the Expert Review Panel are described in Table 5. The panel, at a minimum, should include representation from Hospital Epidemiology, Infectious Diseases, the provider's specialty or subspecialty, Occupational Medicine (ie, the individual involved in monitoring the provider), hospital administration, and, perhaps, legal representation. Each case will be slightly different from the next, and each should be considered independently in context. These subtle differences underscore the importance of the Expert Review Panel. The panel should develop a formal letter or contract delineating its specific recommendations regarding the provider's performance, training in infection control, conduct of specific procedures, follow-up, and management, among other issues (Figure 1). Table 6 provides a list of issues for the infection control professional and the Expert Review Panel to consider when providing advice to infected providers regarding the performance of various procedures. Table 7 provides detail concerning the elements of this letter or contract. The requirement for a twice-annual meeting of the panel may be met by a confidential conference call or secure electronic communication. The Occupational Medicine physician, the infection control professional, and/or the state epidemiologist can serve as gatekeepers for the twice-annual review. So long as the contract is being fulfilled and no guideline violations are identified, additional face-to-face meetings 
Date

Dear Dr. [Name]:

[Hospital or Health Department name]'s Expert Advisory Panel on Infected Healthcare Workers met on [date], to discuss your case. The Panel reviewed the medical literature relevant to healthcare workers infected with [HBV, HCV, HIV]. In addition, we reviewed guidelines, including the 1991 CDC Guideline pertaining to healthcare workers infected with bloodborne pathogens and the position statements of selected medical professional societies pertaining to the guideline. The Panel concluded the following:

You are permitted to continue your [specialty/subspecialty] training or practice at [hospital name]. If you agree to the Panel requirements below, it is mutually understood that you will comply with the following guidelines:

- You must double-glove for all [discipline] procedures, whether those procedures are carried out in the operating room, in an imaging suite, at the bedside, or in a treatment room.

- You must change gloves approximately every 2-3 hours, or in the event that glove damage occurs during a procedure. Glove damage has been shown to occur more frequently during longer procedures, and has been specifically associated with certain activities, (e.g., tying sternal wires). You are encouraged to increase your frequency of glove changes under such circumstances.

- You should avoid digital palpation of needle tips and blind probing in poorly visualized or highly confined anatomic sites.

- If you suffer an injury which penetrates your gloves and skin, but during which you do not observe contact of your blood with the surgical field, you should check your hands to be certain you are not bleeding. If you are not bleeding, you may rejoin the case after changing gloves. If you are bleeding, you should withdraw from the case. If the device that injured you recontacted the patient, you must notify [your representative to the expert review panel] who must assure that the patient is made aware of the potential exposure and is treated appropriately.

- If you suffer an injury that causes you to bleed during a procedure and your blood contacts the surgical field, you must withdraw from the case and contact [your representative to the expert review panel], immediately. She/he will assure that the patient will be informed that a possible [HBV/HCV/HIV] exposure has taken place and the patient will be offered appropriate postexposure management, including immuno-/chemoprophylaxis and follow-up, as appropriate. To the extent possible, your identity will be protected.

- The Panel requests that you continue under the care of a physician with expertise in [HBV/HCV/HIV] medicine in order to appropriately monitor and manage your illness.

If you agree to the outlined restrictions on your practice, please sign below.

Signature: Date:

Witness:

[Name, Expert Advisory Panel Representative] Date:

FIGURE 1. Sample contract letter between an Expert Review Panel and a healthcare provider infected with a bloodborne pathogen. The letter delineates the specific recommendations of the panel and the responsibilities of the panel and of the infected provider. Table 7 provides more detail on the elements of such a letter or contract. 
TAвLE 6. Issues for the Hospital Epidemiologist and the Expert Review Panel to Consider When Providing Advice to Infected Healthcare Providers Regarding the Performance of Various Procedures

1. The precise procedures for which permission is sought, the historical risks for provider-to-patient bloodborne pathogen transmission associated with these procedures, the provider's experience with such procedures, and the likelihood of patient exposure to provider blood during these procedures

2. Gather evidence of the infected provider's skills, practices, and adherence to the institutional infection control plan (particularly with respect to standard precautions)

3. Investigate and discuss with the provider the availability of safer devices that will reduce the risk for patient exposures (eg, spring-loaded retractable needles, guards that shield dangerous tips, and blunted surgical needles)

4. Investigate and discuss the availability of barriers that will reduce the risks for exposures (eg, reinforced gloves, ${ }^{91,92}$ double gloves, gloves constructed of monofilament polymers or other materials resistant to tears, glove-liners, and other devices or materials to protect the provider's hands $s^{89,91,93-96}$ )

5. Discuss work process controls, such as the "hands free" technique in the operating room ${ }^{142}$

6. Emphasize the need and ethical obligation to notify the hospital epidemiologist, immediate supervisor, or other individual, as detailed (or identified) in the contract, should a breach and/or patient exposure occur

7. Emphasize a detailed description of the process to be used in the event of breach of infection control procedures or a patient exposure

of the Expert Review Panel may not be needed. In instances in which guideline violations are identified or in instances in which the provider's clinical status has changed significantly, the entire review panel should meet to consider the new information. The committee emphasizes that the Expert Review Panel should not advise the practitioner about his or her health and treatment options; this responsibility falls to the provider's personal physician.

\section{DISCLOSURE ISSUES}

9. Are there any medical settings in which a healthcare provider infected with HBV, HCV, and/or HIV should be routinely required to notify patients of his or her bloodborne pathogen status; and, if so, what are the specific types of circumstances requiring notification?

\section{Recommendation}

Providers infected with HBV, HCV, and/or HIV who are adhering to the guidelines above should not be required to disclose their infection status to any patient (unless the provider has been the source for an exposure for a patient, as discussed in Recommendation 11A, below) (A-III).

Discussion. Societal views of patients' rights are strong, and most patients feel that they have a right to know if their physician or other healthcare provider is infected with a potentially transmissible bloodborne pathogen (irrespective of the magnitude of risk). ${ }^{118,148,149} \mathrm{~A}$ national survey conducted in 2004 demonstrates little change in public views of this issue. ${ }^{118}$ Case law has generally concluded that informed consent includes disclosure of risks that may be perceived by patients as being important even if, by rational consideration, they are negligible. These positions aside, in both previous versions of this guideline, we concluded that a requirement for such disclosure would very likely require a provider to abandon or substantially modify his or her practice-an un- warranted outcome in light of our current understanding of the risks for provider-to-patient transmission of these bloodborne pathogens. The existing 1991 US Public Health Service guidelines ${ }^{105}$ require that patients who are to have "exposureprone invasive procedures" performed by HIV-positive or $\mathrm{HBeAg}$-positive, HBV-infected practitioners be notified of the practitioner's infection status prior to the procedure. On the basis of the substantial changes in the risk profile since the previous version of this guideline was published (eg, new safety devices, new infection control strategies, better techniques for monitoring diseases, effective postexposure management, and effective therapy), SHEA feels even more strongly that such a position is unwarranted. If practitioners adhere to the components of this guideline with respect to modifying their practices when an increased level of risk is present, in the absence of an adverse patient exposure to blood or blood-containing body fluids (discussed in Recommendation 11, below), the risk for provider-to-patient transmission is so small that it cannot be accurately measured. SHEA's position on these issues remains essentially unchanged. An earlier iteration of the American Hospital Association Patients' Bill of Rights argues for disclosure of relevant information to patients, ${ }^{150,151}$ although this "Bill of Rights" has subsequently been replaced by a plain-language document that does not directly address this issue. The American Medical Association Council on Judicial Affairs also includes a general statement in favor of patient disclosure. ${ }^{152}$

10. Are there circumstances for which an infected healthcare provider should be required to obtain informed consent that includes disclosure of the provider's serostatus from a patient prior to a procedure?

\section{Recommendation}

Providers infected with HBV, HCV, and/or HIV who are adhering to the guidelines above should be required to obtain informed consent for a procedure but should not be required to disclose 
TAble 7. Elements of the Contract between an Infected Healthcare Provider and the Expert Review Panel

Responsibilities of the healthcare provider

1. Agrees to twice yearly follow-up by Occupational Medicine, including measurement of viral burden using tests specified by the panel

2. Agrees to twice yearly evaluations by a private physician who has expertise in the provider's specific bloodborne pathogen infection and agrees to have this physician discuss the results of these evaluations with the provider's Expert Review Panel

3. Agrees to formal training in infection control via a course identified by the infection control expert, or, alternatively agrees to counseling by the infection control professional concerning the use of appropriate infection control procedures, safety devices and work practice controls

4. Agrees to follow the recommended procedures and practices identified in the previous item (responsibility 3 )

5. Agrees to notify the occupational medicine or the public health authority participating in the panel regarding any change in provider status that may increase risk to the patient (eg, new neurological findings, development of another contagious disease [eg, tuberculosis])

6. Acknowledges the ethical obligation to do so, and agrees to report instances immediately in which a patient exposure may have occurred to the hospital epidemiologist or to appropriate institutional/public health authorities identified in the contract, so that the potentially exposed patient may receive appropriate postexposure management and counseling

7. If receiving treatment, agrees to continue treatment as prescribed and agrees to notify occupational medicine if the treatment regimen is modified for any reason

8. Agrees to re-evaluation by expert panel and revision of contract should clinical status or viral burden change Responsibilities of the institution and/or public health authorities

1. Agrees to convene Expert Review Panel at least twice annually (see text) to assess provider's clinical and virologic status as well as the provider's ongoing performance and her or his ability to continue to perform requested procedures

2. Agrees to maintain provider's medical privacy and confidentiality

3. Agrees to develop and follow institutional or provider-based follow-up procedure for potential patient exposure that makes every effort to ensure practitioner confidentiality

4. Panel participants should have no liability

5. Develops process for notifying hospital Risk Management

NOTE. Some aspects of this contract may be mandated by state laws, so the contract should carefully consider the legal requirements for the state in which the contract is being issued. A sample contract letter is shown in Figure 1.

their serostatus as part of the process of informed consent from patients on whom they are about to perform a procedure (A-III).

Discussion. If a practitioner adheres to the guidelines outlined in detail above, SHEA concludes that the risk for transmission would be so small that informed consent about the risk of transmission would not be required. In special circumstances associated with a known or anticipated increased level of risk (eg, a provider who has previously transmitted infection to a patient or a provider who has a viral burden in excess of those listed in these guidelines is performing a Category III procedure), obtaining informed consent is rational, prudent, and advised.

\section{EXPOSURE MANAGEMENT}

\section{How should a provider-to-patient blood exposure or other hazardous body fluid exposure to $\mathrm{HBV}, \mathrm{HCV}$, and/ or HCV be managed?}

11A. Should a provider who is the source of a patient exposure be required to undergo testing for bloodborne pathogen infection?

\section{Recommendation}

A provider who is aware that he or she is the source of a significant patient exposure to his or her blood or hazardous body fluid should undergo testing for infection with bloodborne pathogens, even if not known to be infected with HBV, HCV, and/or HIV (A-III). Healthcare institutions should develop specific policies to deal with such exposures and should establish sanctions for providers who refuse testing for bloodborne pathogens in these circumstances (A-III). Such policies should be formally drawn and approved by institutional attorneys and governing boards (A-III).

\section{Recommendation}

In the event of possible or documented patient exposure to blood or potentially hazardous body fluids from an infected provider, the involved provider is ethically obligated to notify immediately either the Occupational Medicine physician who is conducting follow-up for the provider or the chair of the provider's Expert Review Panel (A-III). Whoever is notified should immediately engage the infection control team, the hospital administration, and institutional risk management team to ensure there is appropriate follow-up and medical management for the potentially exposed patient (A-III). In the event of possible or documented patient exposure to blood or potentially hazardous body fluids from an infected provider who is not institutionally based, the provider is ethically bound to contact the official in the public health establishment who is providing Expert Review Panel oversight (A-III). This individual, in turn, should immediately ensure that there is appropriate follow-up and medical management for the potentially exposed patient (A-III).

Discussion. State laws and State policies and procedures vary substantially with respect to testing for bloodborne path- 
ogens. Healthcare institutions electing to develop policies that compel testing of the source individual should make certain that such polices are legal in their jurisdictions and should apply such policies only to exposures for which scientific precedent establishes that $\mathrm{HBV}, \mathrm{HCV}$, or HIV transmission could occur.

\section{B. Should an inadvertently exposed patient be notified of the exposure?}

\section{Recommendation}

A patient who has been exposed (ie, by way of percutaneous, mucous membrane, or nonintact-skin exposure) to the blood or potentially contaminated body fluid of any provider should be notified of the exposure promptly and given clear options for follow-up testing and management (A-III). An exposed patient (1) should be notified about the exposure promptly; (2) should subsequently be notified of the outcome of the source provider's HBV, HCV, and HIV test results; (3) should receive expert counseling regarding the implications of the event; and (4) should be offered effective postexposure treatment appropriate for the exposure in instances in which an exposure to a bloodborne pathogen is documented (consistent with current CDC guidelines ${ }^{153,154}$ ) (A-III). Institutions should establish policies requiring self-reporting to the infection control program or occupational health program and to the exposed patient's primary physician of provider-to-patient blood or hazardous body fluid exposure (A-III). The exposed patient should not be notified of the source provider's name or of the exact circumstances of the exposure but should be provided with enough information to understand the implications of the exposure fully (A-III).

Discussion. For a variety of reasons, in instances in which a provider-to-patient blood exposure occurs, the patient has a right to know that the exposure has occurred, irrespective of whether the provider is known to be infected with a bloodborne pathogen. The patient must be notified about the exposure and presented with options for postexposure treatment (as appropriate), as well as appropriate follow-up. ${ }^{153,154}$ In addition, the patient must receive counseling about the risk for transmission and the strategies that are effective in preventing subsequent transmission of the bloodborne pathogen to which the patient was exposed. Since any exposure to blood may place patients at risk for acquiring a bloodborne infection, patients should always be notified of such occurrences. The identity of the source (ie, the infected provider) should not be disclosed. Needlestick transmissions (as well as mucous membrane and nonintact-skin transmissions) of HBV, HCV, and HIV infection have all been amply documented. Since negative serologic test results do not completely eliminate the possibility of transmission of bloodborne pathogens, any blood exposure creates a requirement for notification of the exposed patient. Notification also allows the exposed patient to have the option of receiving recommended postexposure management (eg, appropriate chemoprophylaxis or immunoprophylaxis). Institutions should designate a responsible person for informing an exposed patient and ensuring patient follow-up. Ultimate responsibility for follow-up should be assigned to the patient's physician, even if the physician is the source of the exposure. The physician providing the follow-up should receive expert guidance from a member of the Infection Control and/or Occupational Health staff. SHEA would not recommend that the source of the exposure be involved in counseling, informed consent, or test explanation, in light of the potential for conflict of interest. The hospital epidemiologist, infection control practitioner, or other staff knowledgeable both about the risks and routes of transmission of bloodborne pathogens, as well as the counseling of individuals exposed to bloodborne pathogens, should be available for support and consultation.

\section{C. Should an inadvertently exposed patient be required to undergo baseline serologic testing?}

\section{Recommendation}

The exposed patient and his or her physician should be asked for consent to perform baseline testing for bloodborne infections (when consonant with state and/or local laws) (A-III). If consent is obtained, the patient's serum should be tested for evidence of $\mathrm{HBV}, \mathrm{HCV}$, and HIV infection (A-III). If the patient refuses testing, the institution should seek the permission of the patient or the patient's representative to store available baseline serum from the patient (A-III). If neither testing nor storage can be accomplished, the patient or the patient's proxy should be asked to sign a formal declination emphasizing that these services were offered and declined (A-III).

Discussion. Although the exposed patient cannot be compelled to have and may clearly choose not to have such testing performed, such testing would help establish the basis (and some of the best evidence) for a claim against the institution and/or the practitioner. Exposed patients should be made aware of the potential value and detriment of negative and positive test results. For patients who refuse testing (and consonant with state and local laws regarding testing), institutions should attempt to obtain informed consent from the patient to allow the institution to preserve a carefully labeled and dated baseline serum sample from the exposed patient. Although such samples cannot be tested against the patient's will, these samples ultimately represent important evidence in such a case. Patients refusing to consent to serum storage should be asked to sign a form noting their declination for both serologic testing and serum storage.

\section{D. How (and by whom) should an inadvertently exposed patient be followed and, if appropriate, treated?}

\section{Recommendation}

Exposed patients should be counseled regarding the risks for infection and the symptoms of acute HBV, HCV, and HIV infection (A-III), should be offered postexposure chemoprophylaxis and/ or immunoprophylaxis as is characterized in current $\mathrm{CDC}$ guidelines for an exposed healthcare worker ${ }^{153,154}$ (A-II), and should be 
followed in a manner analogous to the existing CDC guidelines for providers who sustain occupational exposures to HIV or other bloodborne pathogens. ${ }^{153,154}$ Institutions and/or providers involved in such exposures should provide testing at no cost to the patient and should provide the details of appropriate follow-up to the patient and her or his physician (A-I).

\section{TESTING ISS UES}

12. Should any, or perhaps all, providers be routinely tested for HIV infection?

\section{Recommendation}

Mandatory HBV, HCV, or HIV screening of healthcare providers is not recommended (A-III). A provider who conducts Category III procedures is ethically obligated to know his or her infection status with respect to HBV, HCV, and HIV (A-III). Institutions should provide voluntary confidential testing for their employees (A-III). A provider who knows that he or she is the source of a patient exposure (ie, as defined by the CDC-a percutaneous, mucous membrane or nonintact-skin exposure) to his or her blood or hazardous blood or body fluid should report the exposure and should undergo testing for infection with bloodborne pathogens (A-III).

\section{LOOK-BACK STUDIES}

13. If an infected provider is identified, under what circumstances should a look-back study be conducted?

\section{Recommendation}

Look-back studies should be conducted only on a case-by-case basis in instances in which compelling evidence for increased risk for provider-to-patient transmission is identified (A-III). A decision to initiate a look-back study should be made in collaboration with the infected provider's Expert Review Panel, institutional leadership, and appropriate local and/or state public health authorities (A-III).

Discussion. Although look-back studies may occasionally provide useful information, most look-back studies have yielded no useful information, and all such investigations are extremely labor-intense and resource-intense. ${ }^{48,57}$ SHEA recommends that such studies be conducted only when factors are identified that suggest an increased risk for provider-topatient transmission of one of these bloodborne pathogens.

A variety of circumstances may prompt initiation of a lookback study. These include (1) if an infected healthcare worker is identified during the investigation of a possible instance of healthcare-associated transmission of one of these viruses, (2) if provider-to-patient transmission infection is documented or presumed, (3) if there is disclosure of a bloodborne pathogen infection associated with a viral burden higher than the thresholds defined in Recommendations 1, 2, and 3 (above), by a healthcare worker who has been conducting Category
III procedures, or (4) if an ongoing screening program identifies an infected healthcare worker who has been conducting Category III procedures and who has a viral burden in excess of the thresholds noted in Recommendations 1, 2, and 3 (above). The goals for such an investigation include (1) the provision of information to patients regarding the nature and magnitude of risks to which they may have been exposed, (2) the identification of patients who may have become infected with one or more of these bloodborne pathogens as a result of healthcare interventions and who may benefit from treatment, (3) the prevention of additional instances of transmission, (4) the management of institutional risks, and (5) the reassurance of the public.

The decision about whether to conduct a look-back study should be made on a case-by-case basis. Factors that would suggest an increased risk for provider-to-patient transmission that would prompt such a study include (1) identification of an infected patient in the practice of an infected provider (and the demonstration of that the patient's and the provider's viral isolates are related), (2) the healthcare provider's clinical specialty and the types of procedures performed are among those associated with increased risk for transmission, (3) concern that a given provider fails to follow recommended infection control procedures, (4) evidence of substandard clinical practice (eg, high postoperative infection rates or frequent occupational exposures), and (5) comorbid medical diagnoses in the infected provider that might elevate risk (eg, conditions resulting in, for example, nonintact skin or early dementia).

The identification of a documented instance of providerto-patient transmission of one of these 3 bloodborne pathogens should invariably result in a thorough look-back exercise. In the absence of a documented instance of providerto-patient transmission, the Expert Review Panel should evaluate the risk for transmission on a case-by-case basis. If a look-back study is implemented, every effort should be made to preserve the privacy and medical confidentiality of the infected provider.

In instances in which the infected provider is institutionally based, the provider's institution should be responsible for the notification program, with appropriate collaboration with the local and state public health authorities. In instances in which the provider is not institutionally based, local or state public health authorities should decide about the need for such a study. If the decision is made to initiate such a study, the decision should be made, and the study conducted, by the appropriate public health authorities.

\section{S U M M A RY}

SHEA favors a comprehensive approach to managing healthcare providers who have been identified as being infected with $\mathrm{HBV}, \mathrm{HCV}$, and/or HIV in the broader context of all institutional health and credentialing programs. Such an ap- 
proach allows the assessment of the provider-to-patient transmission risks in appropriate perspective. Thus, reasons for broadly restricting practice should be consonant with existing impaired-provider and disability guidelines, and should be based on the following criteria: (1) the provider has a viral burden above the recommended threshold for the relevant virus, (2) the provider has a medical condition or conditions resulting in the provider's inability to perform assigned tasks, (3) the provider has documented untoward events (ie, the provider is known to have transmitted HBV, HCV, or HIV), (4) the provider refuses or is unable to follow recommended guidelines to prevent transmission of infectious diseases, and/ or (5) the provider is unable to perform regular duties, assuming that "reasonable accommodation" has been offered for the disability.

\section{A UTHORSHIP STATEMENT}

A subcommittee of the Guidelines Committee of The Society for Healthcare Epidemiology of America drafted this guideline. The SHEA Board of Directors approved the final draft. This consensus statement represents SHEA's position on these controversial issues, and does not represent the opinions of the individual contributors to the document or of individual members of the organization.

Address correspondence to David K. Henderson, MD, Deputy Director for Clinical Care, Clinical Center, National Institutes of Health, Bldg. 10, Rm. 6-1480, 10 Center Dr., MSC 1504, Bethesda, MD 20892-1504 (dkh@ nih.gov).

\section{REFERENCES}

1. Reitsma AM, Closen ML, Cunningham M, et al. Infected physicians and invasive procedures: safe practice management. Clin Infect Dis 2005; 40:1665-1672.

2. Kohn WG, Collins AS, Cleveland JL, Harte JA, Eklund KJ, Malvitz DM. Guidelines for infection control in dental health-care settings-2003. MMWR Recomm Rep 2003; 52:1-61.

3. Centers for Disease Control and Prevention. Possible transmission of human immunodeficiency virus to a patient during an invasive dental procedure. MMWR Morb Mortal Wkly Rep 1990; 39:489-493.

4. Centers for Disease Control and Prevention. Update: Transmission of HIV infection during an invasive dental procedure-Florida. MMWR Morb Mortal Wkly Rep 1991; 40:21-33.

5. Centers for Disease Control and Prevention. Update: investigations of patients who have been treated by HIV-infected health care workers. MMWR Morb Mortal Wkly Rep 1992; 41:344-346.

6. Ciesielski C, Marianos D, Ou C-Y, et al. Transmission of human immunodeficiency virus in a dental practice. Ann Intern Med 1992; 116 : 798-805.

7. Ciesielski CA, Bell DM, Marianos DW. Transmission of HIV from infected health-care workers to patients. AIDS 1991; 5:S93-S97.

8. Ou CY, Ciesielski CA, Myers G, et al. Molecular epidemiology of HIV transmission in a dental practice. Science 1992; 256:1165-2271.

9. Rhame FS, Pitt H, Tapper ML, et al. Position paper: The HIV-infected health care worker. Infect Control Hosp Epidemiol 1990; 11:647-656.

10. Henderson DK, The AIDS/Tuberculosis Subcommittee of the Society for Healthcare Epidemiology of America. Management of healthcare workers infected with hepatitis B virus, hepatitis C virus, human immunodeficiency virus, or other bloodborne pathogens. AIDS/TB Committee of the Society for Healthcare Epidemiology of America. Infect Control Hosp Epidemiol 1997; 18:349-363.

11. Bell D, Shapiro CN, Chamberland ME, CA. C. Preventing bloodborne pathogen transmission from health-care workers to patients: the CDC perspective. Surg Clin North Am 1995; 75:1189-1203.

12. Harpaz R, Von Seidlein L, Averhoff FM, et al. Transmission of hepatitis $B$ virus to multiple patients from a surgeon without evidence of inadequate infection control. $N$ Engl J Med 1996; 334:549-554.

13. Johnston B, Langille D, LeBlanc J, et al. Transmission of hepatitis B related to orthopedic surgery [abstract]. Infect Control Hosp Epidemiol 1994; 15:352.

14. Incident Investigation Teams and others. Transmission of hepatitis B to patients from four infected surgeons without hepatitis B e antigen. N Engl J Med 1997; 336:178-184.

15. Laurenson IF, Jones DG, Hallam NF, Saunders CJ, Fraser DM, Carman WF. Transmission of hepatitis B virus from a vaccinated healthcare worker. J Hosp Infect 2007; 66:393-394.

16. Hepatitis B Outbreak Investigation Team. An outbreak of hepatitis B associated with reusable subdermal electroencephalogram electrodes. CMAJ 2000; 162:1127-1131.

17. Alter MJ. Healthcare should not be a vehicle for transmission of hepatitis C virus. J Hepatol 2008; 48:2-4.

18. Bosch X. Hepatitis C outbreak astounds Spain. Lancet April 8, 2005.

19. Brown P. Surgeon infects patient with hepatitis C. BMJ (Clinical research ed.) 1999; 319(7219):1219.

20. Cody SH, Nainan OV, Garfein RS, et al. Hepatitis C virus transmission from an anesthesiologist to a patient. Arch Intern Med 2002; 162:345350.

21. Duckworth GJ, Heptonstall J, Aitken C. Transmission of hepatitis C virus from a surgeon to a patient. The Incident Control Team. Commun Dis Public Health 1999; 2:188-192.

22. Esteban JI, Gomez J, Martell M, et al. Transmission of hepatitis C virus by a cardiac surgeon. N Engl J Med 1996; 334:555-560.

23. Public Health Laboratory Service. Hepatitis $C$ transmission from health care worker to patient. Commun Dis Rep CDR Wkly 1995; 5:121.

24. Public Health Laboratory Service. Transmission of hepatitis C virus from surgeon to patient prompts lookback. Commun Dis Rep CDR Wkly 1999; 9:387.

25. Public Health Laboratory Service. Hepatitis C lookback exercise. Commun Dis Rep CDR Wkly 2000; 10:203, 206.

26. Public Health Laboratory Service. Two hepatitis C lookback exercisesnational and in London. Commun Dis Rep CDR Wkly 2000; 10:125, 128.

27. Hepatitis C lookback in two trusts in the south of England. Public Health Laboratory Service, 2002. http://www.phls.org.uk/publications/ cdr/PDFfiles/2001/cdr2101.pdf. Accessed November 14, 2002.

28. Ross RS, Viazov S, Roggendorf M. Phylogenetic analysis indicates transmission of hepatitis $\mathrm{C}$ virus from an infected orthopedic surgeon to a patient. J Med Virol 2002; 66:461-467.

29. Ross RS, Viazov S, Thormahlen M, et al. Risk of hepatitis C virus transmission from an infected gynecologist to patients: results of a 7year retrospective investigation. Arch Intern Med 2002; 162:805-810.

30. Williams IT, Perz JF, Bell BP. Viral hepatitis transmission in ambulatory health care settings. Clin Infect Dis 2004; 38:1592-1598.

31. Mawdsley J, Teo CG, Kyi M, Anderson M. Anesthetist to patient transmission of hepatitis $\mathrm{C}$ virus associated with non exposure-prone procedures. J Med Virol 2005; 75:399-401.

32. Shemer-Avni $Y$, Cohen M, Keren-Naus A, et al. Iatrogenic transmission of hepatitis $\mathrm{C}$ virus (HCV) by an anesthesiologist: comparative molecular analysis of the HCV-E1 and HCV-E2 hypervariable regions. Clin Infect Dis 2007; 45:e32-e38.

33. Public Health Laboratory Service. New guidelines on post exposure prophylaxis for HIV. Commun Dis Rep CDR Wkly 2000; 10:311, 314.

34. Pugliese G. Data lacking for postexposure prophylaxis with immune 
serum globulin following HCV exposure. Infect Control Hosp Epidemiol 1994; 15:212.

35. Pugliese G, Favero MS. Healthcare Worker-to-Patient Transmission of HCV in the UK. Infect Control Hosp Epidemiol 2000; 21:619.

36. Ross RS, Viazov S, Gross T, Hofmann F, Seipp HM, Roggendorf M. Transmission of hepatitis $\mathrm{C}$ virus from a patient to an anesthesiology assistant to five patients. $N$ Engl J Med 2000; 343:1851-1854.

37. Sehulster L, Taylor J, Hendricks K, VanEgdom M, Whitely S, Manning $\mathrm{S}$. Hepatitis $\mathrm{C}$ outbreak linked to narcotic tampering in an ambulatory surgical center. In: Proceedings of the Interscience Conference on Antimicrobial Agents and Chemotherapy; 1997. Washington, D.C.: American Society for Microbiology; 1997:293.

38. Centers for Disease Control and Prevention. Transmission of hepatitis $C$ virus infection associated with home infusion therapy for hemophilia. MMWR Morb Mortal Wkly Rep 1997; 46:597-599.

39. Williams IT, Perz JF, Bell BP. Hepatitis C virus transmission from healthcare workers to patients in the United States [abstract]. J Clin Virol 2006; 36:S43-S44.

40. Bosch X. Newspaper apportions blame in Spanish hepatitis C scandal. Lancet 2000; 355:818.

41. Astagneau P, Lot F, Bouvet E, et al. Lookback investigation of patients potentially exposed to HIV type 1 after a nurse-to-patient transmission. Am J Infect Control 2002; 30:242-245.

42. Blanchard A, Ferris S, Chamaret S, Guetard D, Montagnier L. Molecular evidence for nosocomial transmission of human immunodeficiency virus from a surgeon to one of his patients. J Virol 1998; 72:4537-4540.

43. Bosch X. Second case of doctor-to-patient HIV transmission. Lancet Infect Dis 2003; 3:261.

44. Goujon CP, Schneider VM, Grofti J, et al. Phylogenetic analyses indicate an atypical nurse-to-patient transmission of human immunodeficiency virus type 1. J Virol 2000; 74:2525-2532.

45. Lot F, Seguier JC, Fegueux S, et al. Probable transmission of HIV from an orthopedic surgeon to a patient in France. Ann Intern Med 1999; 130: $1-6$.

46. Armstrong FP, Miner JC, Wolfe WH. Investigation of a health care worker with symptomatic human immunodeficiency virus infection: an epidemiological approach. Military Medicine 1987; 152:414-418.

47. Centers for Disease Control and Prevention. Update: Investigations of persons treated by HIV-infected health-care workers-United States. MMWR Morb Mortal Wkly Rep 1993; 42:329-331.

48. Danila RN, MacDonald KL, Rhame FS, et al. A look-back investigation of patients of an HIV-infected physician: public health implications. $N$ Engl J Med 1991; 325:1406-1411.

49. Dickinson GM, Morhart RE, Klimas NG, Bandea CI, Laracuente JM, Bisno AL. Absence of HIV transmission from an infected dentist to his patients: an epidemiologic and DNA sequence analysis. JAMA 1993; 269: $1802-1806$

50. Mishu B, Schaffner W, Horan JM, Wood LH, Hutcheson RH, McNabb PC. A surgeon with AIDS: lack of evidence of transmission to patients. JAMA 1990; 264:467-470.

51. Porter JD, Cruickshank JG, Gentle PH, Robinson RG, Gill ON. Management of patients treated by surgeon with HIV infection. Lancet 1990; 335:113-114.

52. Pretty IA, Anderson GS, Sweet DJ. Human bites and the risk of human immunodeficiency virus transmission. Am J Forensic Med Pathol 1999; 20:232-239.

53. Robert LM, Chamberland ME, Cleveland JL, et al. Investigations of patients of health care workers infected with HIV: the Centers for Disease Control and Prevention database. Ann Intern Med 1995; 122:653657.

54. Rogers AS, Froggatt JW, Townsend T, et al. Investigation of potential HIV transmission to the patients of an HIV-infected surgeon. JAMA 1993; 269:1795-1801.

55. Sacks JJ. AIDS in a surgeon. N Engl J Med 1985; 313:1017-1018.

56. Mascioli SR. More on AIDS in a surgeon. N Engl J Med 1986; 314:1190.

57. von Reyn CF, Gilbert TT, Shaw FE, Jr., Parsonnet KC, Abramson JE,
Smith MG. Absence of HIV transmission from an infected orthopedic surgeon: a 13-year look-back study. JAMA 1993; 269:1807-1811.

58. Chant K, Lowe D, Rubin G, et al. Patient-to-patient transmission of HIV in private surgical consulting rooms. Lancet 1993; 342:1548-1549.

59. Alter HJ. Hepatitis B and the health worker: prospective studies in perspective. Ann Intern Med 1976; 85:971-972.

60. Alter HJ, Chalmers TC. The HBsAg Positive health worker revisited. Hepatology 1981; 1:467-370.

61. Alter HJ, Chalmers TC, Freeman BM, et al. Health-care workers positive for hepatitis B surface antigen: are their contacts at risk? N Engl J Med 1975; 292:454-457.

62. Meyers J, Stamm W, Kwerr M, Counts GW. Lack of transmission of hepatitis B after surgical exposure. JAMA 1978; 240:1725-1727.

63. Williams S, Pattison C, Berquist KR. Dental infection with hepatitis B. JAMA 1975; 232:1231-1233.

64. Campos J, Gonzalez A, Esteban JI, Genesca J, Esteban R, Guardia J. Towards zero risk of posttransfusion hepatitis with 2nd generation antiHCV screening of blood donors (abstract 413). Hepatology 1994; 20: 200A.

65. Henderson DK. Managing occupational risks for hepatitis C transmission in the healthcare setting. Clin Microbiol Rev 2003; 16:546-568.

66. New guidance on hepatitis $\mathrm{C}$ infected health care workers. Public Health Laboratory Service, 2002. http://www.phls.org.uk/publications/cdr/ archive02/News/news3402.html\#hepC. Accessed November 15, 2002.

67. Robert LM, Bell DM. HIV transmission in the health-care setting. Risks to health-care workers and patients. Infect Dis Clin North Am 1994; 8: 319-329.

68. Seeff LB, Wright EC, Zimmerman HJ, Alter HJ, et al. Type B hepatitis after needlestick exposure: prevention with hepatitis B immune globulin: final report of the Veterans' Administration Cooperative Study. Ann Intern Med 1978; 88:285-293.

69. Werner BJ, Grady GF. Accidental hepatitis-B-surface-antigen-positive inoculations: use of "e" antigen to estimate infectivity. Ann Intern Med 1982; 97:367-369.

70. Henderson DK. Human immunodeficiency virus in the healthcare setting. In: Mandell GL, Bennett JE, Dolin R, eds. Principles and Practice of Infectious Diseases. New York, NY: Elsevier; 2010: in press.

71. Gerberding JL, Littell C, Tarkington A, Brown A, Schecter WP. Risk of exposure of surgical personnel to patients' blood during surgery at San Francisco General Hospital. N Engl J Med 1990; 322:1788-1793.

72. Gerberding JL, Ramiro N, Perlman J, Rose D. Intraoperative blood exposures at San Francisco General Hospital: provider injuries and patient recontacts. In: Program and abstracts of the 31st Annual Meeting of the Infectious Diseases Society of America; New Orleans, Louisiana; 1993.

73. Gerberding JL, Rose DA, Ramiro NZ, Perlman JL, Schecter WP. Intraoperative provider injuries and potential patient recontacts at San Francisco General Hospital [abstract]. Infect Control Hosp Epidemiol 1994; 15:20.

74. Lowenfels AB, Mehta V, Levi DA, Montecalvo MA, Savino JA, Wormser GP. Reduced frequency of percutaneous injuries in surgeons: 1993 versus 1988. AIDS 1995; 9:199-202.

75. Lowenfels AB, Wormser GP. Frequency of puncture injuries in surgeons and estimated risk of HIV infection. Arch Surg 1989; 124:1284-1286.

76. Panlilio AL, Foy DR, Edwards JR, et al. Blood contacts during surgical procedures. JAMA 1991; 265:1533-1537.

77. Panlilio AL, Welch BA, Bell DM, et al. Blood and amniotic fluid contact sustained by obstetric personnel during deliveries. Am J Obstet Gynecol 1992; 167:703-708.

78. Popejoy SL, Fry DE. Blood contact and exposure in the operating room. Surg Gynecol Obstet 1991; 172:480-483.

79. Tokars JI, Bell DM, Culver DH, et al. Percutaneous injuries during surgical procedures. JAMA 1992; 267:2899-2904.

80. Elder A, Paterson C. Sharps injuries in UK health care: a review of injury rates, viral transmission and potential efficacy of safety devices. Occup Med (Lond) 2006; 56:566-574. 
81. Sohn S, Eagan J, Sepkowitz KA, Zuccotti G. Effect of implementing safety-engineered devices on percutaneous injury epidemiology. Infect Control Hosp Epidemiol 2004; 25:536-542.

82. Mendelson MH, Lin-Chen BY, Solomon R, Bailey E, Kogan G, Goldbold $\mathrm{J}$. Evaluation of a safety resheathable winged steel needle for prevention of percutaneous injuries associated with intravascular-access procedures among healthcare workers. Infect Control Hosp Epidemiol 2003; 24:105112.

83. Alvarado-Ramy F, Beltrami EM, Short LJ, et al. A comprehensive approach to percutaneous injury prevention during phlebotomy: results of a multicenter study, 1993-1995. Infect Control Hosp Epidemiol 2003; 24:97-104.

84. Aarnio P, Laine T. Glove perforation rate in vascular surgery-a comparison between single and double gloving. VASA 2001; 30:122-124.

85. Centers for Disease Control and Prevention. Evaluation of safety devices for preventing percutaneous injuries among health-care workers during phlebotomy procedures-Minneapolis-St. Paul, New York City, and San Francisco, 1993-1995. MMWR Morb Mortal Wkly Rep 1997; 46:21-25.

86. Centers for Disease Control and Prevention. Evaluation of blunt suture needles in preventing percutaneous injuries among health-care workers during gynecologic surgical procedures-New York City, March 1993June 1994. MMWR Morb Mortal Wkly Rep 1997; 46:25-29.

87. Tarantola A, Golliot F, L'Heriteau F, et al. Assessment of preventive measures for accidental blood exposure in operating theaters: a survey of 20 hospitals in Northern France. Am J Infect Control 2006; 34:376382.

88. Wicker S, Jung J, Allwinn R, Gottschalk R, Rabenau HF. Prevalence and prevention of needlestick injuries among health care workers in a German university hospital. Int Arch Occup Environ Health 2008; 81: 347-354.

89. Akduman D, Kim LE, Parks RL, et al. Use of personal protective equipment and operating room behaviors in four surgical subspecialties: personal protective equipment and behaviors in surgery. Infect Control Hosp Epidemiol 1999; 20:110-114.

90. Comer RW, Myers DR, Steadman CD, Carter MJ, Rissing JP, Tedesco FJ. Management considerations for an HIV-positive dental student. J Dent Educ 1991; 55:187-191.

91. Alrawi SJ, Houshan I, Zanial SA, Cunningham JN, Jr., Acinapura AJ, Raju R. Cardiac surgical procedures and glove reinforcements. Heart Surg Forum 2002; 5:66-68.

92. Weber LW. Evaluation of the rate, location, and morphology of perforations in surgical gloves worn in urological operations. Appl Occup Environ Hyg 2003; 18:65-73.

93. Bebbington MW, Treissman MJ. The use of a surgical assist device to reduce glove perforations in postdelivery vaginal repair: a randomized controlled trial. Am J Obstet Gynecol 1996; 175:862-866.

94. Leslie LF, Woods JA, Thacker JG, Morgan RF, McGregor W, Edlich RF. Needle puncture resistance of surgical gloves, finger guards, and glove liners. J Biomed Mater Res 1996; 33:41-46.

95. Salkin JA, Stuchin SA, Kummer FJ, Reininger R. The effectiveness of cut-proof glove liners: cut and puncture resistance, dexterity, and sensibility. Orthopedics 1995; 18:1067-1071.

96. Woods JA, Leslie LF, Drake DB, Edlich RF. Effect of puncture resistant surgical gloves, finger guards, and glove liners on cutaneous sensibility and surgical psychomotor skills. J Biomed Mater Res 1996; 33:47-51.

97. Hartley JE, Ahmed S, Milkins R, Naylor G, Monson JR, Lee PW. Randomized trial of blunt-tipped versus cutting needles to reduce glove puncture during mass closure of the abdomen. Br J Surg 1996; 83:11561157.

98. Mingoli A, Sapienza P, Sgarzini G, et al. Influence of blunt needles on surgical glove perforation and safety for the surgeon. Am J Surg 1996; 172:512-516.

99. Wright KU, Moran CG, Briggs PJ. Glove perforation during hip arthroplasty: a randomised prospective study of a new taperpoint needle. J Bone Joint Surg Br 1993; 75:918-920.
100. Bennett NT, Howard RJ. Quantity of blood inoculated in a needlestick injury from suture needles. J Am Coll Surg 1994; 178:107-110.

101. Harpaz R, Van Seidlein L, Averhoff F, et al. Hepatitis B virus transmission associated with cardiothoracic surgery. In: Proceedings of the 33rd Interscience Conference on Antimicrobial Agents and Chemotherapy; 1993; New Orleans, Louisiana: American Society for Microbiology; 1993.

102. Centers for Disease Control and Prevention. Summary and recommendations for preventing transmission of infection with human Tlymphotropic virus type III/lymphadenopathy- associated virus in the workplace. MMWR Morb Mortal Wkly Rep 1985; 34:681-686, 91-95.

103. Gioananni P, Sinicco A, Cariti G, Lucchini A, Paggi G, Giachino O. HIV infection acquired by a nurse. Eur J Epidemiol 1988; 4:119-120.

104. Fahey BJ, Koziol DE, Banks SM, Henderson DK. Frequency of nonparenteral occupational exposures to blood and body fluids before and after universal precautions training. Am J Med 1991; 90:145-153.

105. Centers for Disease Control and Prevention. Recommendations for preventing transmission of human immunodeficiency virus and hepatitis $\mathrm{B}$ virus to patients during exposure-prone invasive procedures. $M M W R$ Morb Mortal Wkly Rep 1991;40:1-9. http://www.cdc.gov/mmwr/ preview/mmwrhtml/00014845.htm. Accessed January 8, 2010.

106. Tarantola A, Abiteboul D, Rachline A. Infection risks following accidental exposure to blood or body fluids in health care workers: a review of pathogens transmitted in published cases. Am J Infect Control 2006; 34:367-375.

107. Sundkvist T, Hamilton GR, Rimmer D, Evans BG, Teo CG. Fatal outcome of transmission of hepatitis B from an e antigen negative surgeon. Commun Dis Public Health 1998; 1:48-50.

108. Hoofnagle JH, Doo E, Liang TJ, Fleischer R, Lok AS. Management of hepatitis B: summary of a clinical research workshop. Hepatology 2007; 45:1056-1075.

109. UK Department of Health. Hepatitis C infected health care workers. 2002. http://www.dh.gov.uk/en/Publicationsandstatistics/Publications/ PublicationsPolicyAndGuidance/DH_4010554. Accessed January 26, 2009.

110. Dienstag JL, McHutchison JG. American Gastroenterological Association technical review on the management of hepatitis C. Gastroenterology 2006; 130:231-264.

111. Seeff LB, Hoofnagle JH. National Institutes of Health Consensus Development Conference: management of hepatitis C: 2002. Hepatology 2002; 36:S1-S2.

112. Strader DB, Wright T, Thomas DL, Seeff LB. Diagnosis, management, and treatment of hepatitis C. Hepatology 2004; 39:1147-1171.

113. Alberti A, Boccato S, Vario A, Benvegnu L. Therapy of acute hepatitis C. Hepatology 2002; 36:S195-S200.

114. Jaeckel E, Cornberg M, Wedemeyer $\mathrm{H}$, et al. Treatment of acute hepatitis C with interferon alfa-2b. N Engl J Med 2001; 345:1452-1457.

115. Wiegand J, Deterding K, Cornberg M, Wedemeyer H. Treatment of acute hepatitis C: the success of monotherapy with (pegylated) interferon alpha. J Antimicrob Chemother 2008; 62:860-865.

116. Fabris P. Acute hepatitis C: epidemiology, pathogenesis and therapy. Curr Pharm Des 2008; 14:1644-1645.

117. UK Department of Health. HIV Infected Health Care Workers: Guidance on Management and Patient Notification. 2005. http://www.dh .gov.uk/en/Publicationsandstatistics/Publications/PublicationsPolicy AndGuidance/DH_4116415. Accessed January 26, 2009.

118. Tuboku-Metzger J, Chiarello L, Sinkowitz-Cochran RL, Casano-Dickerson A, Cardo D. Public attitudes and opinions toward physicians and dentists infected with bloodborne viruses: results of a national survey. Am J Infect Control 2005; 33:299-303.

119. Closen ML. HIV-AIDS, infected surgeons and dentists, and the medical profession's betrayal of its responsibility to patients. NY Law Sch Law Rev 1996; 41:57-139.

120. DiMaggio SL. State regulations and the HIV-positive health care professional: a response to a problem that does not exist. Am J Law Med 1993; 19:497-522. 
121. UK Department of Health. Hepatitis B Infected Health Care Workers: guidance on Implementation of Health Service Circular 2000/020. 2000. http://www.dh.gov.uk/en/Publicationsandstatistics/Publications/ PublicationsPolicyAndGuidance/DH_4008156. Accessed January 26, 2009.

122. UK Department of Health. Hepatitis B infected healthcare workers and antiviral therapy. 2007. http://www.dh.gov.uk/en/Publicationsand statistics/Publications/PublicationsPolicyAndGuidance/DH_073164. Accessed January 26, 2009.

123. Gunson RN, Shouval D, Roggendorf M, et al. Hepatitis B virus (HBV) and hepatitis $\mathrm{C}$ virus (HCV) infections in health care workers (HCWs): guidelines for prevention of transmission of HBV and HCV from HCW to patients. J Clin Virol 2003; 27:213-230.

124. Buster EH, van der Eijk AA, Schalm SW. Doctor to patient transmission of hepatitis B virus: implications of HBV DNA levels and potential new solutions. Antiviral Res 2003; 60:79-85.

125. van der Eijk AA, de Man RA, Niesters HG, Schalm SW, Zaaijer HL. Hepatitis B virus (HBV) DNA levels and the management of HBVinfected health care workers. J Viral Hepat 2006; 13:2-4.

126. FitzSimons D, Francois G, De Carli G, et al. Hepatitis B virus, hepatitis $\mathrm{C}$ virus and other blood-borne infections in healthcare workers: guidelines for prevention and management in industrialised countries. Осcup Environ Med 2008; 65:446-451.

127. UK Department of Health. Health clearance for tuberculosis, hepatitis B, hepatitis C and HIV: New healthcare workers. 2007. http://www .dh.gov.uk/en/Publicationsandstatistics/Publications/Publications PolicyAndGuidance/DH_073132. Accessed January 26, 2009.

128. Centers for Disease Control and Prevention. Recommendations for prevention of HIV transmission in health-care settings. MMWR Morb Mortal Wkly Rep 1987; 36(Suppl 2):1S-18S.

129. Do AN, Ciesielski CA, Metler RP, Hammett TA, Li J, Fleming PL. Occupationally acquired human immunodeficiency virus (HIV) infection: national case surveillance data during 20 years of the HIV epidemic in the United States. Infect Control Hosp Epidemiol 2003; 24:86-96.

130. Centers for Disease Control and Prevention. Recommendations for preventing transmission of infection with human T-lymphotropic virus type III/lymphadenopathy-associated virus during invasive procedures. MMWR Morb Mortal Wkly Rep 1986; 35:221-223.

131. Centers for Disease Control and Prevention. Update: universal precautions for prevention of transmission of human immunodeficiency virus, hepatitis B virus, and other bloodborne pathogens in health-care settings. MMWR Morb Mortal Wkly Rep 1988; 37:377-382.

132. Centers for Disease Control and Prevention. Public Health Service statement on management of occupational exposure to human immunodeficiency virus, including considerations regarding zidovudine postexposure use. MMWR Morb Mortal Wkly Rep 1990; 39:1-14.

133. Centers for Disease Control and Prevention, Division of Safety, National Institutes of Health. Occupationally acquired human immunodeficiency virus infections in laboratories producing virus concentrates in large quantities: conclusions and recommendations of an expert team convened by the Director of the National Institutes of Health (NIH). MMWR Morb Mortal Wkly Rep 1988; 37(Suppl 4):19-22.

134. Gross PA, Barrett TI, Dellinger EP, et al. Purpose of quality standards for infectious diseases. Clin Infect Dis 1994; 18:421.

135. The periodic health examination. Canadian Task Force on the Periodic Health Examination. Can Med Assoc J 1979;121:1193-1254.

136. Alter HJ, Seeff LB, Kaplan PM, et al. Type B hepatitis: the infectivity of blood positive for e antigen and DNA polymerase after accidental needlestick exposure. N Engl J Med 1976; 295:909-913.
137. Ippolito G, Puro V, Heptonstall J, Jagger J, De Carli G, Petrosillo N. Occupational human immunodeficiency virus infection in health care workers: worldwide cases through September 1997. Clin Infect Dis 1999; 28:365-383.

138. Puro V, Petrosillo N, Ippolito G. Risk of hepatitis C seroconversion after occupational exposures in health care workers. Italian Study Group on Occupational Risk of HIV and Other Bloodborne Infections. Am J Infect Control 1995; 23:273-277.

139. Bell DM, Shapiro CN, Culver DH, Martone WJ, Curran JW, Hughes JM. Risk of hepatitis B and human immunodeficiency virus transmission to a patient from an infected surgeon due to percutaneous injury during an invasive procedure: estimates based on a model. Infect Agents Dis 1992; 1:263-269.

140. Henderson DK, Saah AJ, Zak BJ, et al. Risk of nosocomial infection with human T-cell lymphotropic virus type III/lymphadenopathy-associated virus in a large cohort of intensively exposed health care workers. Ann Intern Med 1986; 104:644-647.

141. Corden S, Ballard AL, Ijaz S, et al. HBV DNA levels and transmission of hepatitis B by health care workers. J Clin Virol 2003; 27:52-58.

142. Stringer B, Haines T. Hands-free technique: preventing occupational exposure during surgery. J Perioper Pract 2006; 16:495-500.

143. Buster EH, van der Eijk AA, de Man RA, Janssen HL, Schalm SW. Prolonged antiviral therapy for hepatitis B virus-infected health care workers: a feasible option to prevent work restriction without jeopardizing patient safety. J Viral Hepat 2007; 14:350-354.

144. Stringer B, Infante-Rivard C, Hanley JA. Effectiveness of the hands-free technique in reducing operating theatre injuries. Occup Environ Med 2002; 59:703-707.

145. Nash KL, Bentley I, Hirschfield GM. Managing hepatitis C virus infection. BMJ 2009; 338:b2366.

146. Manns MP, McHutchison JG, Gordon SC, et al. Peginterferon alfa-2b plus ribavirin compared with interferon alfa- $2 b$ plus ribavirin for initial treatment of chronic hepatitis C: a randomised trial. Lancet 2001; 358(9286):958-965.

147. Fried MW, Shiffman ML, Reddy KR, et al. Peginterferon alfa-2a plus ribavirin for chronic hepatitis C virus infection. N Engl J Med 2002; 347(13):975-982.

148. Gerbert B, Bleecker T, Berlin M, Coates TJ. HIV-infected health care professionals: public opinion about testing, disclosing, and switching. Arch Intern Med 1993; 153:313-320.

149. Gerbert B, Maguire B, Hulley S, Coates T. Physicians and acquired immunodeficiency syndrome: What patients think about human immunodeficiency virus in medical practice. JAMA 1989; 262:1969-1972.

150. American Hospital Association (AHA). Patients' bill of rights. Chicago, IL: AHA; 1975.

151. American Hospital Association (AHA). Management of HIV infection in the hospital. 3rd ed. Chicago, IL: AHA; 1988.

152. American Medical Association (AMA). Current opinions of the Council on Ethical and Judicial Affairs of the American Medical Association. Chicago, IL: AMA; 1986.

153. Panlilio AL, Cardo DM, Grohskopf LA, Heneine W, Ross CS. Updated U.S. Public Health Service guidelines for the management of occupational exposures to HIV and recommendations for postexposure prophylaxis. MMWR Recomm Rep 2005; 54:1-17.

154. Centers for Disease Control and Prevention. Updated U.S. Public Health Service Guidelines for the Management of Occupational Exposures to $\mathrm{HBV}, \mathrm{HCV}$, and HIV and Recommendations for Postexposure Prophylaxis. MMWR Morb Mortal Wkly Rep 2001; 50:1-52. 